\title{
Analysis of a Standard Sample of Natural Gas by Laboratories Cooperating with the American Society for Testing Materials
}

\author{
By Martin Shepherd ${ }^{12}$
}

\begin{abstract}
This is a report of the analysis of a standard sample of natural gas by 30 laboratories cooperating with Subcommittee VII of Committee D-3 of the American Society for Testing Materials. The data are presented in a series of frequency distribution plots that show at a glance how the analyses from all laboratories compare with respect to each component determined, as well as calculated heating value and specific gravity. The heating value and specific gravity determined by analysis are compared with values carefully measured at the National Bureau of Standards. The analyses were performed volumetrically by the absorption and combustion methods, and the plots form a clear picture of this type of gas analysis in this country. Although some very creditable work is reported, the need for standardization is evident.
\end{abstract}

\section{Introduction}

Subcommittee VII of Committee D-3 of the American Society for Testing Materials has been assigned the task of standardizing the analysis of gaseous fuels. This is the second of a series of reports concerned with work preliminary to actual standardization. In the first of these reports ${ }^{2}$ it was stated that the subcommittee was approaching their assigned task with certain reservations derived from an acquaintance with gas analysis methods, gas analysis apparatus, and gas analysts. The reason for such reservations usually becomes apparent when a gas analyst is asked to substitute a new reagent, pipette, procedure, methodor a whole new apparatus or system of analysisfor one that he has been using satisfactorily. Such a request is unamiable and might very often

${ }_{1}^{1}$ Chairman of Subcommittee VII (Analysis of Gaseous Fuels) of Committee D-3 (Gaseous Fuels), American Society for Testing Materials.

2 Martin Shepherd, Analysis of a standard sample of the carburetted water-gas type by laboratories cooperating with the American Society for Testing Materials, J. Research NBS 36, 313 (1946) RP1704.

Analysis of Standard Sample of Natural Gas be unreasonable. Indeed, if it can be demonstrated by actual measurement that an apparatus or method now in use will give satisfactory results, there is no real justification for insisting that it be discarded in favor of another that may be sponsored as the official instrument of some group.

As it seems reasonable and fair to approve any apparatus and method capable of giving satisfactory analytical results, it remains only to decide what are satisfactory analytical results and which methods and apparatus will yield these results. To reach these decisions, two steps are being taken.

First, the various purposes to be served by the analytical data are listed, and the necessary accuracy with which each component of each type of fuel gas must be known in order to serve each specific purpose is then estimated. These estimates afford the first criterion by means of which the suitability of analytical methods and apparatus may be judged, but they are subject to revision when more is known about the limiting attainable 
accuracies of the analytical methods and also when the significance of the term "necessary" in the phrase "necessary accuracy" has been evaluated with more realism than enthusiasm.

Second, the accuracy and reproducibility of existing apparatus and methods are being measured by the direct procedure of conducting a series of cooperative analyses of standard gas samples of various types. (Although these samples are being prepared at the National Bureau of Standards, they are not to be confused with the Bureau's series of Standard Samples available for purchase. These gas samples are being prepared for free distribution to laboratories cooperating with ASTM D-3 in this project).

The cooperative analytical results obtained so far represent the first clear picture of the actual state of gas analysis in this country.

\section{Cooperating Laboratories}

These analyses are being conducted on a considerable scale. Cooperating laboratories include those of State and Federal agencies and of colleges, but the greatest contribution has come from the laboratories of the gas, petroleum, steel, and chemical industries. The laboratories are located throughout the United States. They are equipped with many types of apparatus, almost entirely modern, and employ different analytical methods. The type of apparatus used in the analysis of this sample is noted with the presentation of the analytical data. Of the 30 laboratories which analyzed the natural-gas sample, all but one (a college) employed chemists specifically trained in gas analysis. Taken as a whole, the work represents the best present-day American practice.

\section{Preparation of Standard Gas Sample ASTM D-3-VII-2}

Standard sample ASTM D-3-VII-2, natural gas type, was prepared to conform with the range of composition accepted for this test sample by Subcommittee VII:

$\begin{array}{lr}\mathrm{O}_{2} & 0 \text { to } 15 \\ \mathrm{~N}_{2} & 0 \text { to } 5 \\ \mathrm{CH} & 2 \\ \mathrm{C}_{2} \mathrm{H}_{6} & \text { to } 50 \\ \mathrm{C}_{3} \mathrm{H}_{8} & 0 \text { to } 50\end{array}$
Heating value _... 1,080 to $1,140 \mathrm{Btu} / \mathrm{ft}^{3}$

Specific gravity _. 0.630 to 0.750

The sample was made up from the following compressed gases obtained from commercial sources:

\begin{tabular}{|l|l|c|}
\hline & $\begin{array}{c}\text { Approximate } \\
\text { purity }\end{array}$ & Chief impurity \\
\hline & $\begin{array}{c}\text { Perrent } \\
\end{array}$ & \\
\hline $\mathrm{CO}_{2}$ & 99.98 & $\mathrm{Air}$ \\
$\mathrm{N}_{2}$ & 99.9 & $\mathrm{O}_{2}$ \\
$\mathrm{CH}_{4}$ & 98 & $\mathrm{~N}_{2}$ and $\mathrm{C}_{2} \mathrm{H}_{6}+$ \\
$\mathrm{C}_{2} \mathrm{H}_{6}$ & $\mathrm{C}_{2} \mathrm{H}_{4}$ and $\mathrm{C}_{3} \mathrm{H}_{8}$ \\
$\mathrm{C}_{3} \mathrm{H}_{8}$ & $\mathrm{C}_{4} \mathrm{H}_{10}$ \\
\hline
\end{tabular}

As this sample was not prepared from gases of known high purity, its actual composition with respect to all components is not known. It was definitely established that no significant amount of oxygen (i. e., less than 0.02 percent by volume) occurred in the sample. In addition, its heating value and specific gravity were carefully measured. The sample, therefore, has four definite purposes, as it serves to measure (1) reproducibility, ${ }^{3}$ (2) accuracy of the computed specific gravity, (3) relation between the measured and the computed heating value, (4) ability to determine correctly absence of oxygen in gas mixtures of this type. It will not serve as a final criterion of accuracy (see footnote 3 ), since its exact composition is not known. $^{4}$

The sample was prepared under a pressure of $300 \mathrm{lb} / \mathrm{in}^{2}{ }^{2}$ in the large storage and mixing tank used to prepare the mixtures for the Bureau's study of specific gravity instruments. ${ }^{5}$ After very thorough mechanical mixing, the uniformity of the

3 Lest there be any confusion as to the meaning of the terms accuracy and reproducibility, it should be stated that the conventional concepts are here implied. Accuracy is measured in terms of agreement with a true value; reproducibility is measured in terms of the mutual agreement of a series of measurements of the same property of a substance. As a matter of convenience, reproducibility has long served the gas analyst in lieu of a definite measurement of accuracy. Eventually this situation will be corrected.

"Such terms as "known mixture" or "synthetic sample" are rather too lightly used in the literature. Unless the composition of a mixture is known to one order of magnitude better than may be expected from an analytical method, analysis of the mixture cannot be considered a measurement of the accuracy of the analytical method. If a mixture is "known," the purity (exact composition) of each component must have been measured to a greater significance than the method used for its analysis will yield, and the portioning of each component to form the mixture must have been done in such a way that the relative amounts of all present are known again to a greater significance than they can be resolved by analysis. To make such a mixture usually seems too difficult, and the "synthetic sample" usually invoked may not be truly definitive.

${ }^{5}$ F. A. Smith, J. H. Eiseman, and E. C. Cretiz, Tests of instruments for the determination, indication, or recording of the specific gravities of gases, NBS Miscellaneous Publication M177. (1947.) 
whole sample was definitely established by sampling from various parts of the tank and intercomparing these portions by means of a 1-m Zeiss gas interferometer to detect any difference in composition. This interierometer is sensitive to changes of 0.01 percent or less of carbon dioxide and methane which were part of the standard sample. The sample was then transferred to small sample cylinders as follows:

1. The sample cylinders, equipped with needle valves having vacuum-tight packing, were connected to a single welded manifold by means of high-pressure unions. The large mixing tank and a vacuum pump were connected to this same manifold. The manifold and opened sampling cylinders were evacuated to $0.0001 \mathrm{~mm} \mathrm{Hg}$ pressure overnight. Thereafter, with vacuum pump disconnected, the increase of pressure within this system was less than $0.0005 \mathrm{~mm}$ during the first hour. Only a few minutes were required to transfer the gas sample from the mixing tank to the sample cylinders. No significant contamination from leakage was possible under these conditions.

2. The small cylinders were flushed with the sample from the mixing tank by alternate filling to 2 atmospheres and evacuating to $1 \mathrm{~mm} \mathrm{Hg}$. After the third flushing, the sample cylinders were filled to $300 \mathrm{lb} / \mathrm{in}^{2}$. With full pressure on the manifold, the sample cylinders were then closed. The manifold was then opened to a water seal, and no leakage from the cylinders was observed overnight.

3. All of the sample cylinders issued for the cooperative analysis of this sample were thus filled simultaneously from the manifold connected to the single uniform source of supply. The samples were, therefore, identical at the date of issue.

To avoid contamination while transferring the sample to the burette, the following illustrated instructions for a definite procedure were furnished the laboratories.

\section{INSTRUCTIONS REGARDING SAMPLER AND SAMPLING}

1. The cylinder containing the sample is shipped in a metal case made from standard pipe fittings. Save this for return of the cylinder, which must be returned immediately upon completion of your analyses.

2 . The cylinder is equipped with a very special vacuumtype needle valve. DO NOT close this valve with anything but the thumb and one finger. Do NoT force the valve shut. If too much twist is applied to the valve handle, the seat will be ruined.

3. Remove the dust cap from the valve and attach the sampling fitting, which terminates in a thin brass tapered sleeve. This sleeve fits a standard glass interchangeable joint, male part, size $\overline{\$} 10 / 30$. This glass joint should be sealed to the brass sleeve by a thermoplastic cement of the DeKhotinsky type, or other cement capable of making a gas-tight joint. We find the arrangement sketched below desirable.

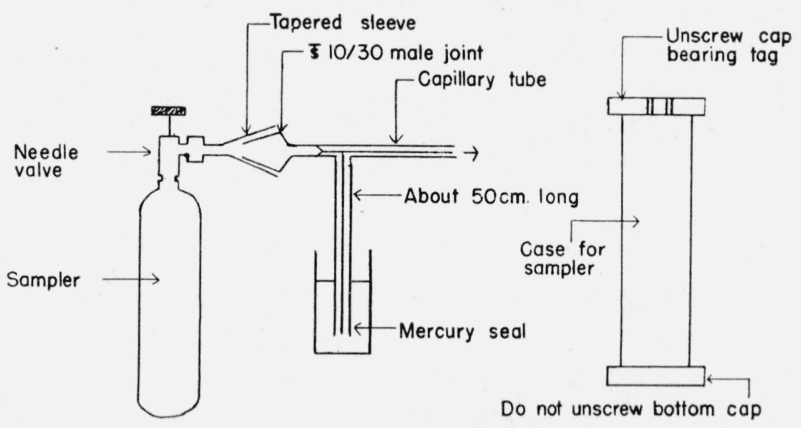

FIGURE 1.-Flow diagram for sampling assembly.

With cock of burette closed, gently open needle valve until gas bubbles out through mercury seal. When this line is flushed, take gas into burette and discard until horizontal portion of sampling line is flushed. About 50 $\mathrm{ml}$ in all is adequate for flushing capillary lines. Leave connected to burette for next sample to be taken. Use mercury seal as manometer to avoid sampling under reduced pressure. If direct glass seal or interchangeable joint is not used in connecting to burette, flush sampling line each time with about $20 \mathrm{ml}$ of gas. For convenience and safety, we prefer interchangeable joints secured with DeKhotinsky or a heavy lubricant.

In no case did any analyst who made any of these determinations have any other knowledge of the properties of this sample, nor was any information other than that given above imparted to anyone until all of the laboratories represented in this account had reported. During 1941, the specific gravity was measured by E. C. Creitz and the heating values by J. H. Eiseman, both of the National Bureau of Standards. These values were turned over to the author, who, as chairman of Subcommittee VII, did not engage in the analyses conducted at this Bureau, nor did he consult these values until the Bureau's analyses, performed by Shuford Schuhmann, had been reported to him.

In July 1944, R. S. Jessup, of this Bureau, redetermined the heating value. Also, during 1944, there were three determinations of composition made with the Bureau's mass spectrometer (manufactured by the Consolidated Engineering 
Co.) under the charge of A. Keith Brewer. As the cooperative analyses had not then been reported, the first two measurements by the mass spectrometer could not have been made with a knowledge of the previously obtained results. The third analysis was made by Vernon H. Dibeler after all the other results from all sources had been reviewed by him, and proper corrections had been made for hydrogen. (See discussion in section $\mathrm{V}, 12$.)

\section{Apparatus and Methods Used for Analysis of Standard Gas Sample}

\section{Apparatus}

It has been stated that most of the analytical apparatus used in this cooperative investigation was of the modern type. The apparatus may be classified with respect to the system of volume measurement, the arrangement of pipettes or reaction tubes, and the confining fluid. For convenience, a set of abbreviations may be used.

$\mathrm{V}_{1}$-Volumes are made comparable by means of a pressure-temperature compensator with manometer interposed between the compensating tube and the burette.

$\mathrm{V}_{2}$ - Pressure within the burette is balanced against existing barometric pressure, and gas volumes are corrected from the observed pressure and temperature to a common basis, including a correction for changes in the saturation pressure of water.

$\mathrm{V}_{3}$-Pressure in burette is balanced against atmospheric pressure but no correction is made for changes in pressure or temperature during analysis.

$\mathrm{V}_{4}$-Volumes are measured by observing the pressure exerted within a constant volume.

$\mathrm{R}_{1}$-Pipettes are connected to the burette by a manifold.

$\mathrm{R}_{2}-\mathrm{A}$ single pipette, connected to the burette, serves for all reactions.

$\mathrm{R}_{3}$-Pipettes are temporarily connected in succession to the burette as the different reactions are progressively conducted.

$\mathrm{R}_{4}$ - The burette itself serves as a reaction tube.

$\mathrm{Hg}$-Mercury is used as the confining fluid.

$\mathrm{H}_{2} \mathrm{O}$ (with appropriate subscript)-An aqueous solution serves as the confining fluid.
Thus the abbreviation $\mathrm{V}_{1} \mathrm{R}_{1} \mathrm{Hg}$ designates an apparatus equipped with pressure-temperature compensator and manometer, manifold connecting pipettes to burette, with mercury serving as the confining fluid; 23 of the 30 laboratories used this type of apparatus. Three laboratories used a $\mathrm{V}_{2} \mathrm{R}_{1} \mathrm{Hg}$ type of apparatus, two used a $\mathrm{V}_{2} \mathrm{R}_{1} \mathrm{H}_{2} \mathrm{O}$ type, another a Hemple apparatus $\left(\mathrm{V}_{2} \mathrm{R}_{3} \mathrm{Hg}\right)$, another a $\mathrm{V}_{3} \mathrm{R}_{2} \mathrm{H}_{2} \mathrm{O}$ type, and finally one used a Bone and Wheeler apparatus, widely employed in Great Britain $\left(\mathrm{V}_{4} \mathrm{R}_{2} \mathrm{Hg}\right)$.

\section{Methods of Analysis}

In general, the method of analysis used involved the conventional four steps, as follows:

Method A:

1. Absorption of carbon dioxide in an aqueous solution of potassium hydroxide.

2. Absorption of oxygen in alkaline pyrogallol or in a chromous solution.

3. A single combustion over hot paltinum in the presence of excess oxygen, measurement of the contraction and carbon dioxide produced, and computation of all hydrocarbons present as $\mathrm{CH}_{4}$ and $\mathrm{C}_{2} \mathrm{H}_{6}$, using the conventional formulas:

$$
\begin{aligned}
\mathrm{CH}_{4} & =1 / 3\left(4 T C-5 \mathrm{CO}_{2}\right) \\
\mathrm{C}_{2} \mathrm{H}_{6} & =1 / 3\left(4 \mathrm{CO}_{2}-2 T C\right),
\end{aligned}
$$

where $T C$ is the total contraction on burning, and $\mathrm{CO}_{2}$ is the carbon dioxide produced by the combustion.

4. Nitrogen by difference.

Although 23 of the laboratories used this method, there were a few notable exceptions. Four of the laboratories employed the following method:

\section{Method B:}

1 and 2 as in method $A$.

(One of the four laboratories then took fresh portions of the sample for combustion, correcting the combustion data for the $\mathrm{CO}_{2}$ and $\mathrm{O}_{2}$ originally found. The other three used the general procedure of combustion of a portion of the sample taken for absorption.) 
3. A single combustion over hot platinum in the presence of excess oxygen, measurement of the contraction, carbon dioxide produced, oxygen consumed, and the unreacted residue, and computation of all hydrocarbons as $\mathrm{CH}_{4}$ and $\mathrm{C}_{2} \mathrm{H}_{6}$ using the formulas:

$$
\begin{aligned}
& \mathrm{CH}_{4}=1 / 3\left[7\left(T C+\mathrm{CO}_{2}\right)-9 \mathrm{O}_{2}\right] \\
& \mathrm{C}_{2} \mathrm{H}_{6}=1 / 3\left[6 \mathrm{O}_{2}-4\left(T C+\mathrm{CO}_{2}\right) ?\right.
\end{aligned}
$$

4. Nitrogen reported as the measured unreacted residue.

Method $B$ has the advantage of eliminating from the combustion data the additive errors caused by the deviation of $\mathrm{CO}_{2}$ from ideality, the loss of $\mathrm{CO}_{2}$ by solution in water formed or originally present, and the loss of $\mathrm{CO}_{2}$ in any rubber connections. All of these errors result in too high a contraction and too low a produced carbon dioxide. ${ }^{6}$ It will be shown that the few laboratories using this method reported more consistent results than the group as a whole. Whether or not this consistency would persist if the method were used by all of the laboratories is yet to be determined.

In addition to the two chemical methods just outlined, there were a few departures. One laboratory employed one of the procedures ordinarily used for the analysis of a fuel of the carburetted water-gas type. This procedure, method II described in a previous report (see footnote 2), included absorption of unsaturated hydrocarbons in fuming sulfuric acid and a fractional combustion over copper oxide, both preceding the combustion over hot platinum in the presence of excess oxygen.

In addition to these chemical methods, two laboratories used procedures involving distillation as follows:

\footnotetext{
${ }_{6}^{6}$ This has been repeatedly demonstrated. See Martin Shepherd, An improved apparatus and method for the analysis of gas mixtures by combustion and absorption, BS J. Research 6, 121-167 (1931) R P266; Martin Shepherd and Joseph R. Branham, Critical study of the determination of ethane by combustion over platinum in the presence of excess oxygen, BS J. Research 11, 783 (1933) RP625; Joseph R. Branham and Martin Shepherd, Critical study of the determination of ethane by explosion with oxygen or air, J. Research NBS 13, 377 (1934) R P715; Joseph R. Branham, Martin Shepherd, and Shuford Schuhmann, Critical study of the determination of carbon monoxide by combustion over platinum in the presence of excess oxygen, J. Research NBS 26, 571 (1941) RP1396.
}

Method X:

1. $\mathrm{CO}_{2}$ and $\mathrm{O}_{2}$ by absorption in a separate sample.

2. A single combustion of the hydrocarbons, with measurement of contraction and carbon dioxide produced.

3. A separation of the hydrocarbons by distillation in one of the usual rectifying columns.

4. Correction of the combustion data to take account of hydrocarbons heavier than $\mathrm{C}_{2} \mathrm{H}_{6}$.

Also, one laboratory employed only distillation for the analysis of the hydrocarbon fraction:

Method $Y$ :

1. $\mathrm{CO}_{2}$ and $\mathrm{O}_{2}$ separately by absorption.

2. Other components by distillation.

Finally, this sample was analyzed by the Consolidated mass spectrometer, under the direction of A. Keith Brewer at the National Bureau of Standards.

It will be shown that two of the laboratories employing these special methods contributed the maximum and minimum calculated heating values-respectively about 50 and $40 \mathrm{Btu}$ on either side of the measured values.

\section{Results of Cooperative Analysis of Standard Gas Sample}

\section{Manner of Presenting the Analytical Data}

All the analytical data submitted have been tabulated, together with the average values derived from each series of analyses, but contemplation of these tabulated data for some hours would not serve to reveal what may be seen at a glance when the same data are presented in a series of frequency-distribution plots. Accordingly, these plots, which amount to actual pictures of the analytical data, are presented first, and the discussion is centered around them. The tabulated data are given in an appendix, without discussion, but with sufficient explanation concerning their arrangement to permit their detailed study by those interested. (See table 1, page 40.)

Each circle appearing on the frequency-distribution plots represents a value derived from a single analysis. The circles are plotted equidistant on 
the ordinate corresponding to their value. Thus the abscissas are values derived from the analyses, and the ordinates indicate the frequency with which these values occur. For example, in the plot showing the distribution of the results of the analyses for carbon dioxide (fig. 2) it will be seen

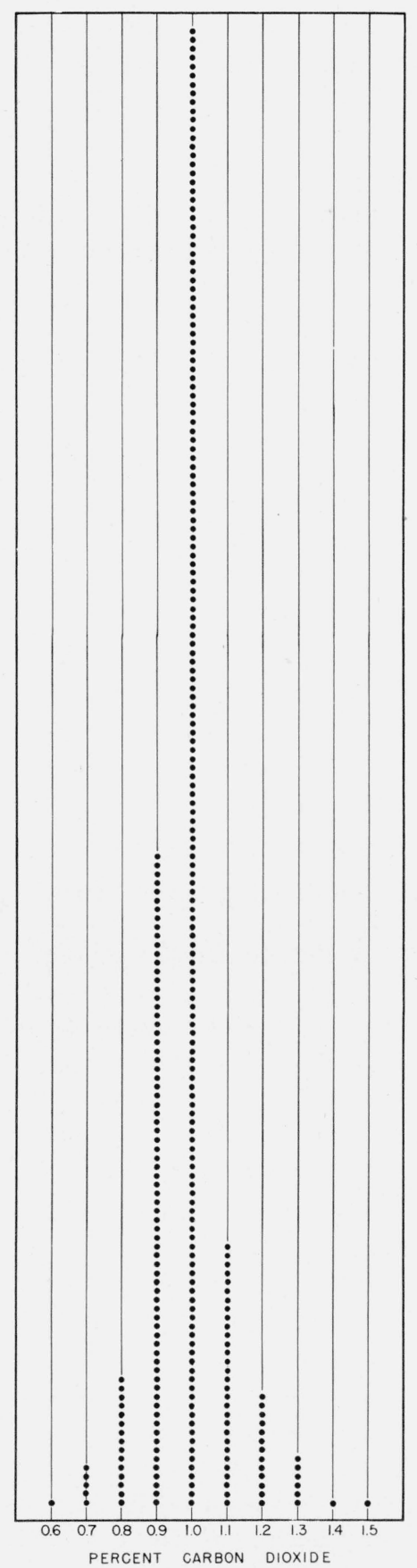

Figure 2.-Frequency-distribution plot for carbon dioxide-0.1 percent interval. that 1 analysis gave 0.6 percent $\mathrm{CO}_{2}, 5$ analyses gave 0.7 percent, 15 analyses gave 0.8 percent, and so on. This manner of plotting shows the distribution of all of the results at a glance, and forms the basis of a probability curve, of which the maxima are the most probable values. These graphical pictures not only save hours of study of the tabulated data, but actually make the significance of the data so self-evident that lengthy and detailed discussion of each plot is hardly necessary.

\section{Carbon Dioxide}

All the analyses reported for carbon dioxide are given in this plot (fig. 2). Analyses reported to hundredths of a percent were rounded off to the nearest tenth percent. Figure 3 is a separate plot

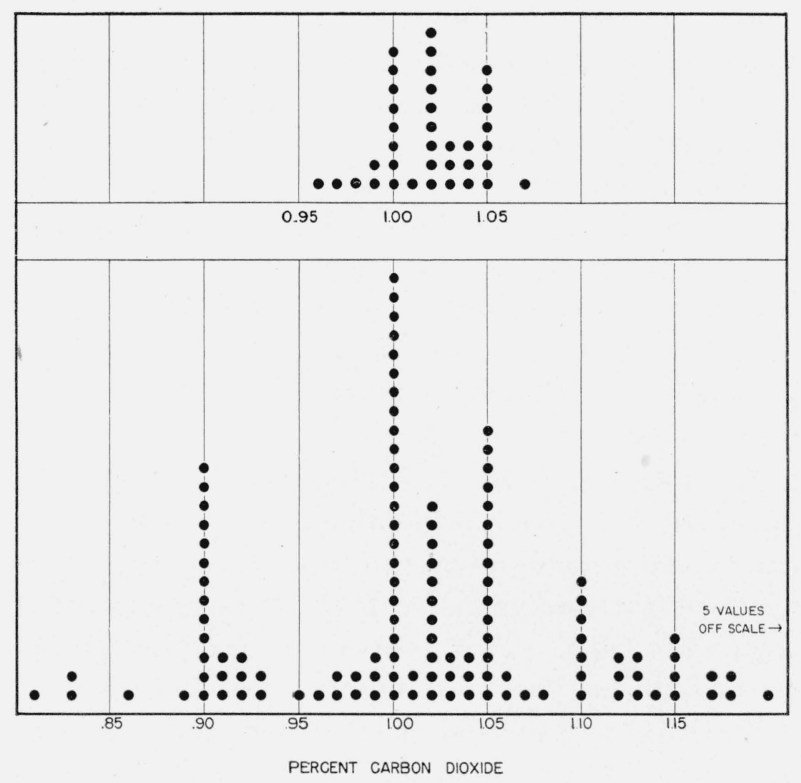

Figure 3.-Frequency-distribution plot for carbon dioxide0.01 percent interval.

of those analyses which were reported to hundredths of a percent. (The tendency to round off to the nearest 0.05 percent is apparent.) The upper section of this plot gives the results of four laboratories that have generally been in agreement during this series of cooperative analyses, and probably represents the best reproducibility to be hoped for between laboratories with this type of sample. The total spread in this group is less than that noted for the whole group and suggests the desirability of taking the little extra trouble to adjust pressures and read volumes rather carefully. 
The greatest frequency occurs at 1.0 percent. Of the 313 analyses reported for this constituent, 271 are between 0.9 and 1.1 percent. These results are not unsatisfactory, but can be improved.

\section{Oxygen}

The analyses for oxygen are plotted in figure 4 . These are particularly interesting as there was no significant amount of oxygen in the sample. One or two-tenths of a percent of oxygen is usually

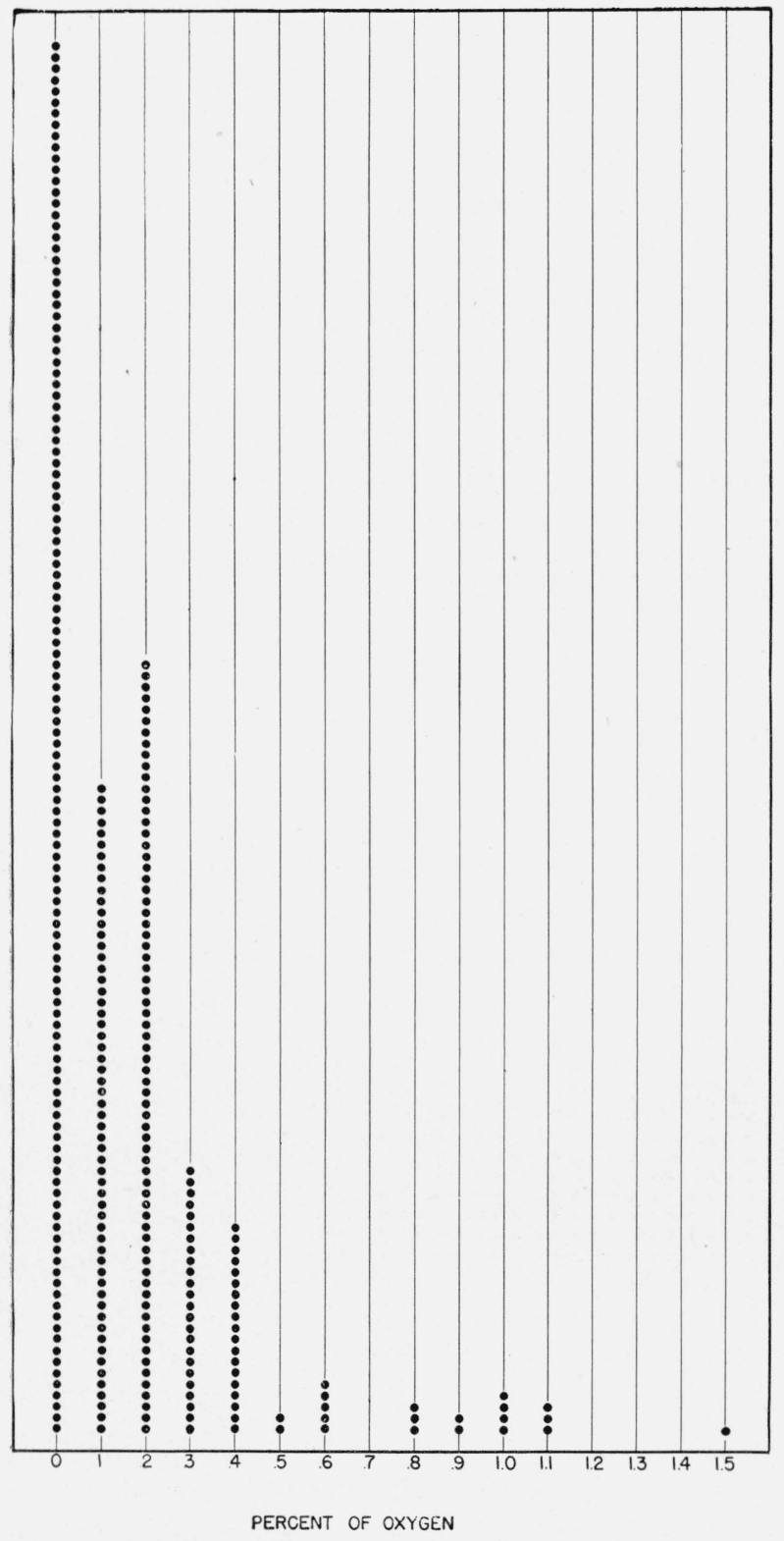

FIGURE 4.-Frequency-distribution plot for oxygen-0.1 percent interval. reported in the analysis of a natural gas, and the extent to which oxygen really does occur has long been a question. Other constituents of the gas will dissolve in the reagents used to remove oxygen, and it is accordingly necessary to saturate these reagents with respect to the other gases and to maintain this equilibrium throughout the analysis. If this is correctly done, the error of solubility, leading to an erroneously high value for oxygen, should be minimized or eliminated. The present analyses show the extent to which this procedure has been successfully applied. Of the 294 analyses reported, 124 (only 42 percent) correctly indicated no oxygen; 58 (about 20 percent) indicated 0.1 percent oxygen, which may be considered the average error of solubility that experience has shown may be expected; and 69 (about 23 percent) indicated 0.2 percent oxygen, which should have been the maximum error caused by solubility alone. However, 24 and 19 analyses indicated 0.3 and 0.4 percent, respectively, and these values round off the probability curve. Beyond this, there are 20 values between 0.5 and 1.5 percent, which probably were the result of air contamination during the transfer of the sample to the analytical apparatus.

It will be shown later that the heating values computed from the analyses indicating no oxygen are in general higher than those reported by the whole group.

\section{Methane}

The data for methane are given in two plots, figures 5 and 6 . In the first of these, methane is plotted to the nearest half percent; in the second plot, 36 values have been eliminated before plotting to the nearest tenth percent.

Referring to the first plot (fig. 5), the greatest frequency appears at 77 percent, with an average of 76.5 percent if values lower than 73.5 and higher than 80.0 are discarded. The range 73.5 to 80.0 , which includes about 94 percent of all the analyses, is rather wider than could be desired. The analyses were generally reported to the nearest tenth percent, although some were noted to hundredths. When plotted to the nearest tenth (fig. 6, section $A+B$ ) the whole group loses the sharp peak near 77 percent, and the distribution becomes widespread. This plot has been separated into two sections, and the letters $A$ and $B$, correspond to the two methods previously 


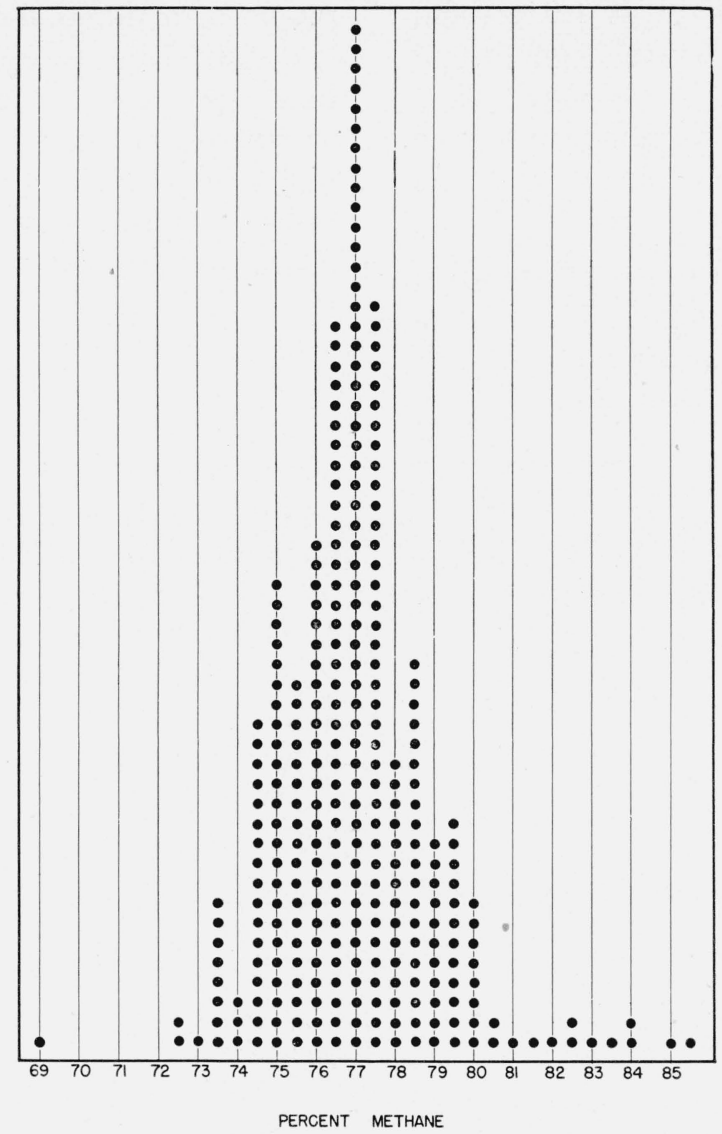

FiguRE 5.-Frequency-distribution plot for methane-0.5 percent interval.

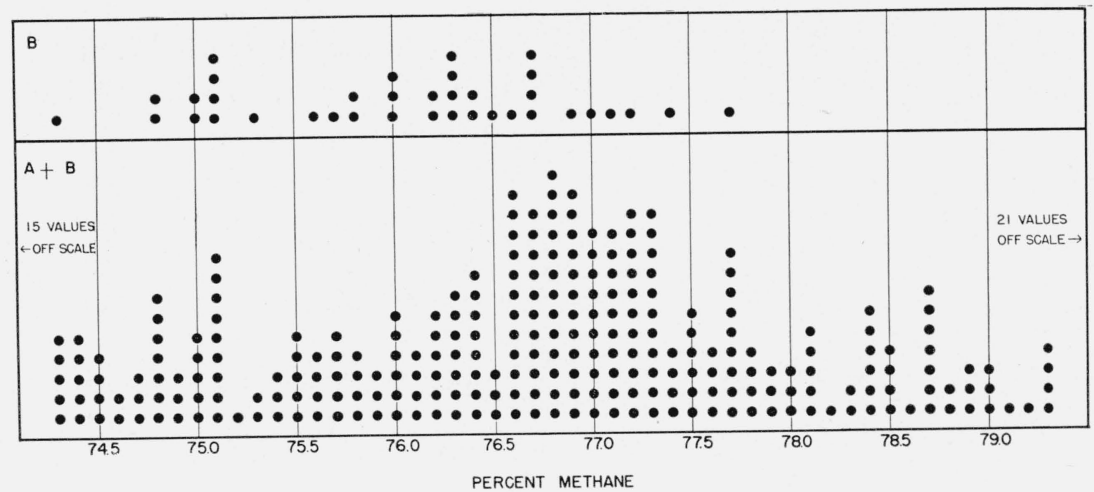

Figure 6.-Frequency-distribution plot for methane-0.1 percent interval.

noted. The upper section gives the analyses reported by the four laboratories that used method $B$, which takes account of oxygen consumed during the combustion as well as the contraction and carbon dioxide produced. Although these values are still widely spread, they are more closely grouped than is true for all of the analyses. (Note that none is off scale.) Group $B$ indicates a somewhat lower average value, 76.1 percent, for methane. 


\section{Ethane}

The analyses for ethane are given in two plots, figures 7 and 8, which follow the same scheme used for plotting methane. The first plot (fig. 7) shows the greatest frequency to be at 18.5 per- cent. About 89 percent of the analyses lie in the range 17.0 to 21.5 percent, with an average value of 19 percent. The analyses are plotted to the nearest tenth percent in section $A+B$ of figure 8 . The distribution is again wide, even more so than is shown, for 31 values have been

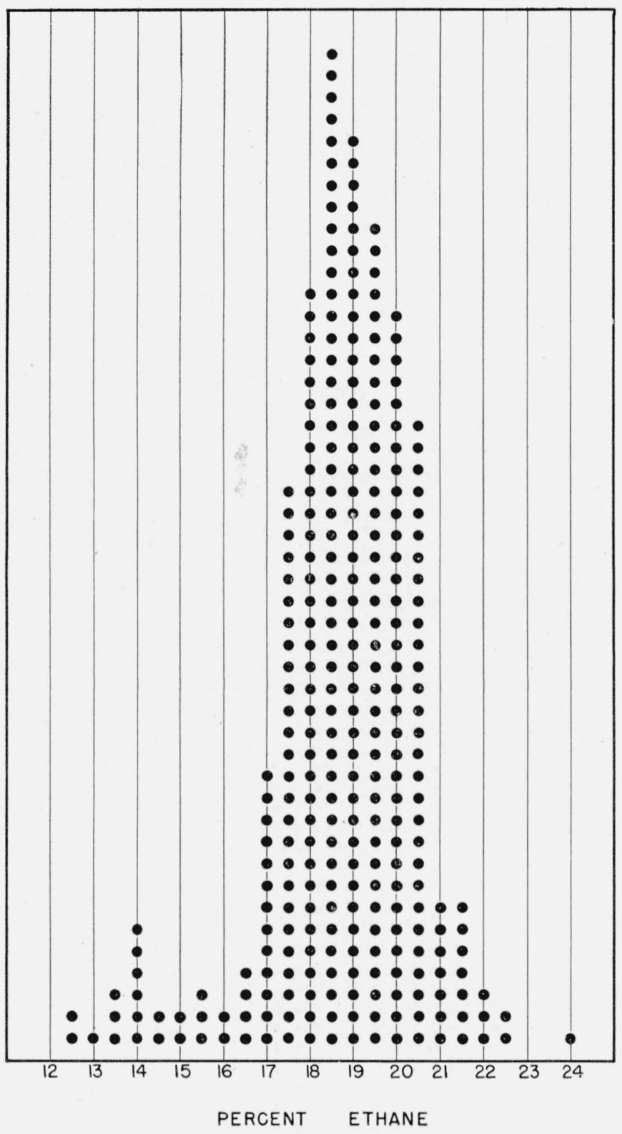

FIGURE 7.-Frequency-distribution plot for ethane-0.5 percent interval.

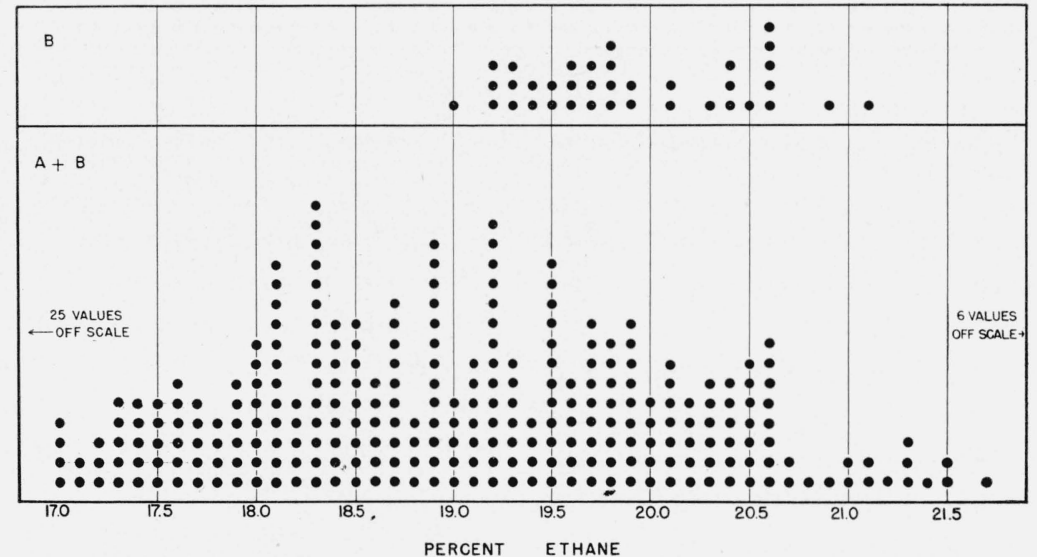

FiguRe 8.-Frequency-distribution plot for ethane-0.1 percent interval. 
dropped. The values noted in the upper section of this plot, yielded by method $B$, are more closely clustered and are higher than the whole group. The average is 19.9 .

\section{Nitrogen}

Nitrogen is always of especial interest in a combustion analysis, because no matter what method is used for the combustion the nitrogen (or more properly, the inert fraction), should always be the same. It is a measure of completeness of combustion and may indicate leakage during sampling or the analysis. In the case of method $B$, nitrogen is measured as an unreacted residue, while it is computed by difference from 100 percent in method $A$. The analyses for nitrogen are plotted to the nearest tenth percent in figure 9. This scale corresponds to the scale used in figures 4,6 , and 8 . A condensed scale (0.5 percent) for nitrogen, to correspond to the scale of figures 5 and 7 , has not been presented,

\section{Calculated and Measured Specific Gravity}

The accuracy with which the specific gravity was computed from these analyses has been directly determined, since the specific gravity of this standard sample was measured by E. C. Creitz, of the National Bureau of Standards. ${ }^{7}$ The measured value was definitely known to one or two orders of magnitude more than could be expected from the analytical data. The measured value (referred to dry $\mathrm{CO}_{2}$-free air $=1$ ) was 0.6820 \pm 0.00005 , and this has been indicated on the plot (fig. 10), which shows the values calculated from all of the analyses, plotted to the nearest 0.002 . The calculated values were all computed from the following values given in the International Critical Tables:

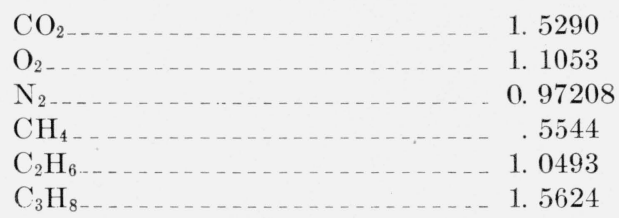

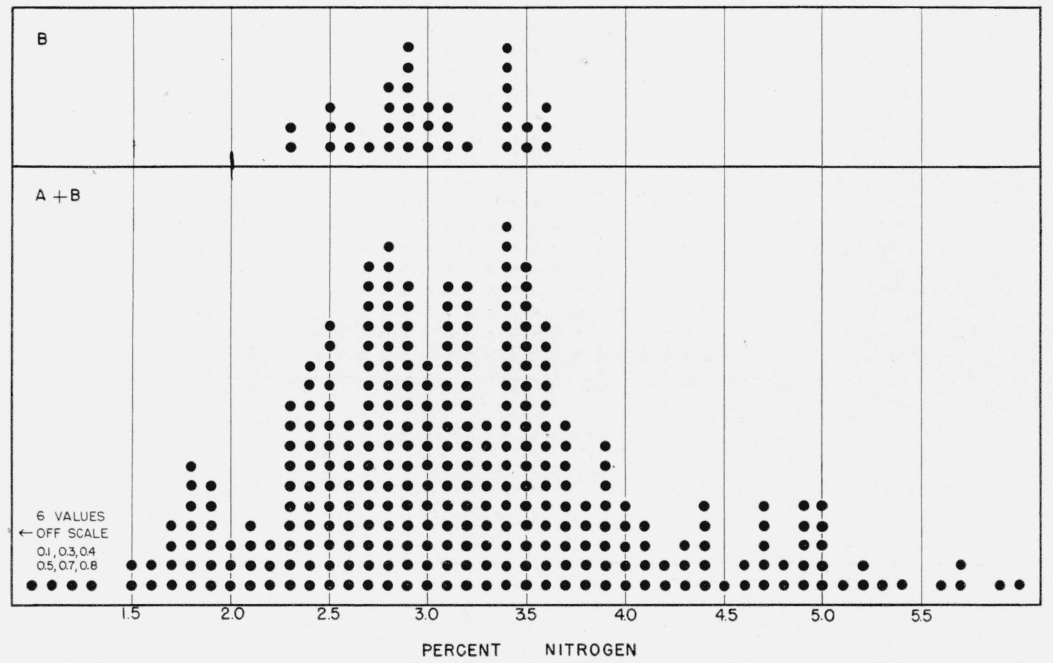

Figure 9.-Frequency-distribution plot for nitrogen-0.1 percent interval.

even though it was not possible to include all of the analyses in figure 9. Note that six values are off scale to the left.

The plot for nitrogen shows a rather wide distribution. Values reported for method $B$ are more closely grouped than is found in the over-all picture, but the average, 3.0, differs only slightly from that of the whole group, which is 3.1 for the range 1.5 to 5.0 percent.
The greatest frequency is noted at 0.672 , lower than the measured value by 0.010 or 1.5 percent. The calculated specific gravities are plotted to the nearest 0.001 in figure 11 , section $A+B$. Although the greatest frequency is still seen at 0.671 to 0.672 , the distribution now appears rather wide. Section $B$ shows the values given by method $B$, and in this case the distribution is still

7 See footnote 5 . 


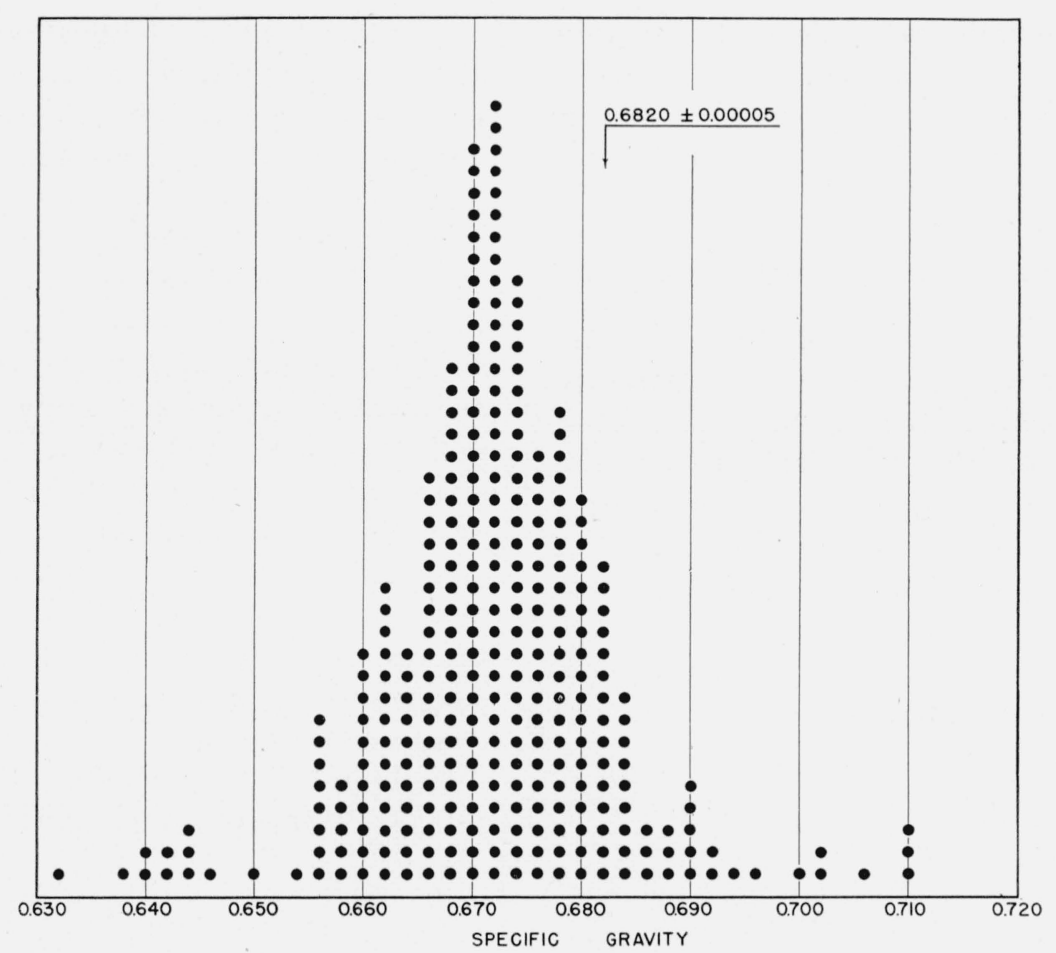

FiguRE 10.-Frequency-distribution plot for calculated specific gravity-0.002 interval.

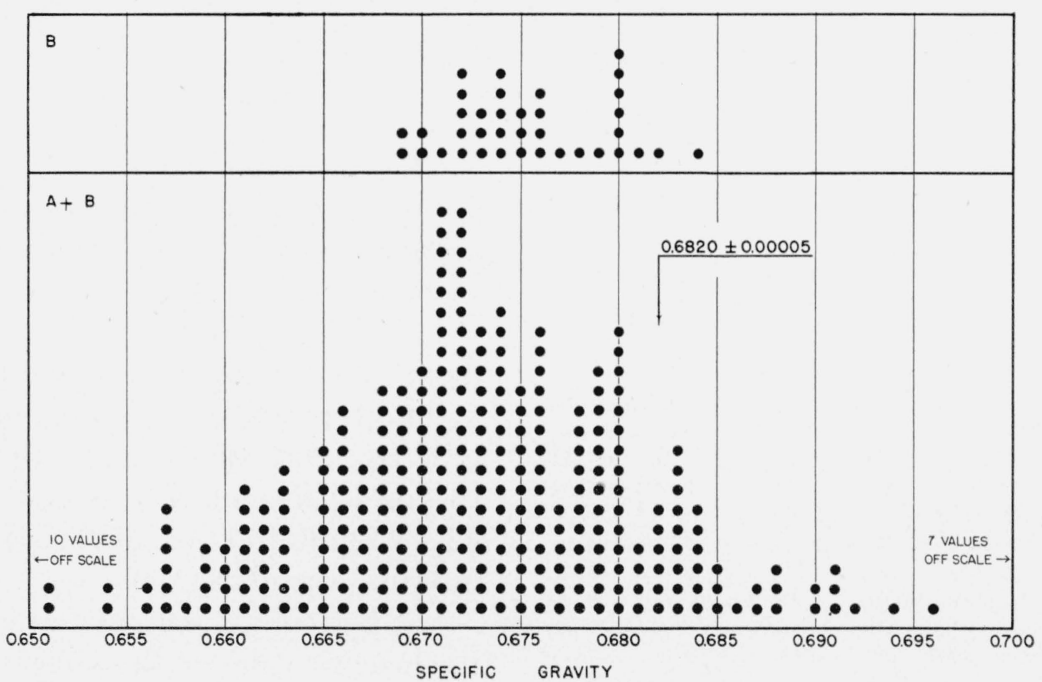

FIGURE 11.-Frequency-distribution plot for calculated specific gravity-0.001 interval.

wide, although the range is considerably improved. If 37 of the 272 values are eliminated, the average of the whole group from 0.657 to 0.685 (about 88 percent of all values reported) is 0.672 , or 1.5 percent too low. The average of the $B$ group is 0.675 , somewhat closer to the measured value, although 1 percent too low.

Analysis of Standard Sample of Natural Gas
A comparison with the specific gravity measured by the various instruments ordinarily used for this determination shows a generally better score for laboratory type instruments designed for this measurement, but a somewhat spotty score for recording instruments. Three specific-gravity balances yield average values of $0.680,0.682$, and 
0.681. An effusion apparatus gave the average value $0.689,1$ percent too high. One recorder gave the correct value, 0.682 , but three others recorded the values $0.690,0.687$, and 0.696 , too high, by 1.2, 0.7, and 2.0 percent, respectively.

\section{Calculated and Measured Heating Value}

Because the heating value of this standard sample was measured, it is possible to estimate the accuracy with which the heating value was calculated from the analyses. Unfortunately, this estimation cannot be made as closely as desired because of the uncertainty in the measured heating value. Two series of measurements were made with the Junkers calorimeter, the first by J. H. Eiseman and the second by R. S. Jessup. The following values were obtained:

\begin{tabular}{|c|c|c|}
\hline & \multicolumn{2}{|c|}{$\mathrm{Btu} / \mathrm{ft}^{3}, 60^{\circ} \mathrm{C}, 30$ in. $\mathrm{Hg}$} \\
\hline & $\begin{array}{l}1100.7 \\
1097.4 \\
1098.5\end{array}$ & $\begin{array}{r}\mathrm{a}(1102.4) \\
(1099.1) \\
(1100.2)\end{array}$ \\
\hline Average $\ldots . . . .$. & $\begin{array}{l}1098.9 \\
1106.6 \\
1108.5 \\
1107.9\end{array}$ & $\begin{array}{l}(1100.6) \\
(1107.8) \\
(1109.5) \\
(1109.1)\end{array}$ \\
\hline Average .... & 1107. 9 & (1109. 1) \\
\hline $\begin{array}{l}\text { Average of the two } \\
\text { series }\end{array}$ & 1103 & $(1105)$ \\
\hline
\end{tabular}

a Since this report was first issued for study by the ASTM Committees involved, Mr. Jessup has recomputed the measured heating values according to the new procedures of ASTM Tentative Method of Test for Calorific Value of Gaseous Fuels by the Water-Flow Calorimeter. This tentative method has been approved by Committees ASTM D-3 and D-3-III, ASTM designatian D-900-46T. The values in parentheses are those obtained by the new computation, which makes a correction of the measured heat of combustion to the standard temperature of $60^{\circ} \mathrm{F}$. The original values noted on the frequency distribution plots have not been altered, although officiai action of the ASTM will probably make this desirable eventually.

In addition to the Junkers determinations, other independent measurements were made. The Thomas recording calorimeter gave the value 1,100 $\mathrm{Btu} / \mathrm{ft}^{3}$ at the time the first Junkers series yielded the value 1,099. In addition, the values 1,099 and 1,102 were obtained from a measurement of the heat of combustion of this sample and a measurement of the carbon dioxide produced on combustion. These values were derived as follows:
(1) The heat of combustion was measured by J. W. Knowlton according to the procedures described for the determination of the heats of combustion of methane and carbon monoxide. ${ }^{8}$ Three calorimetric experiments were performed at a mean temperature of $25^{\circ} \mathrm{C}$, with the water vapor, but not the carbon dioxide, removed from the sample prior to combustion. The heat of combustion so determined was $842.68 \pm 0.20$ international kilojoules per mole $(44.010 \mathrm{~g})$ of $\mathrm{CO}_{2}$ collected after combustion.

(2) The stoichiometric relationship between sample and $\mathrm{CO}_{2}$ present after combustion was determined volumetrically by burning the sample (containing its original $\mathrm{CO}_{2}$ ) over hot platinum in the presence of excess oxygen in an all-glass apparatus. ${ }^{9}$ Seven determinations were made by Shuford Schuhmann.

Volume of $\mathrm{CO}_{2}$ present after combustion of 1.0000 volume of sample ASTM-2:

$$
\begin{gathered}
\text { 1. } 1679 \\
1.1677 \\
1.1672 \\
1.1678 \\
1.1665 \\
1.1681 \\
1.1669 \\
\text { Average__ } \\
\hline 1.1674 \pm 0.0005
\end{gathered}
$$

The tabulated values represent the measured decrease in volume when the carbon dioxide was absorbed from the mixture of oxygen, nitrogen, and carbon dioxide after the combustion of 1.0000 volume of gas, corrected for the measured carbon dioxide originally in the sample. The measurements were made at approximately $25^{\circ} \mathrm{C}$ and 760 $\mathrm{mm} \mathrm{Hg}$, corresponding to the conditions during the measurement of the heat of combustion (1). The volume fraction of the carbon dioxide in the mixture was about 0.6 .

(3) By combining measurements (1) and (2). the heating value of the sample may be calculated,

Converting int. $\mathrm{kj} /$ mole of $\mathrm{CO}_{2}$ to Btu/mole of $\mathrm{CO}_{2}: \frac{842.68}{1.05460}=799.05 \mathrm{Btu} / \mathrm{mole}$ of $\mathrm{CO}_{2}$ present after combustion.

8 Frederick D. Rossini, The heat of formation of water, BS J. Research 6, 1 (1931) R P259; The heats of combustion of methane and carbon monoxide, $\mathbf{6}$, 37 (1931) R P260; The heat of formation of water and the heats of combustion of methane and carbon monoxide. A correction, 7,329 (1931) RP343.

9 A modification of the analytical apparatus described in BS J. Research 6 , 121 (1931) RP266, with the manometer-compensator described in J. Research NBS 26, 351 (1941) RP1382, and all rubber connections eliminated. 
Converting Btu/mole of $\mathrm{CO}_{2}$ to $\mathrm{Btu} / \mathrm{ft}^{3}$ of $\mathrm{CO}_{2}$ (in the ideal gas state at $0^{\circ} \mathrm{C}$ and $760 \mathrm{~mm}$ of mercury): $799.05 \mathrm{Btu} / 22.4140$ liters= $=1009.46 \mathrm{Btu} /$ 28.3162 liters or per $\mathrm{ft}^{3}$ of $\mathrm{CO}_{2}$.

Converting this expression to the condition 30 in $\mathrm{Hg}, 60^{\circ} \mathrm{F}$, saturated: $\frac{273.16}{288.71} \frac{762-13.25}{760} 1009.46$ $=940.95 \mathrm{Btu} / \mathrm{ft}^{3}$ of $\mathrm{CO}_{2}$ (ideal gas) present after burning this sample, at 30 in $\mathrm{Hg}, 60^{\circ} \mathrm{F}$, saturated.

It now remains to correct the carbon dioxide measured volumetrically after combustion for deviation from ideality. This correction introduces the greatest uncertainty in the present calculation:

The partial pressure of $\mathrm{CO}_{2}$ in the residual volume after combustion was approximately 0.6. Under the conditions of the experiment (nearly $25^{\circ} \mathrm{C}$ and $\left.1 \mathrm{~atm}\right)$, the deviation of $\mathrm{CO}_{2}$ from ideality is 0.0051 , which is to say that it occupies only 0.9949 of the volume 1.0000 , which represents the ideal condition. However, the actual deviation of $\mathrm{CO}_{2}$ mixed with the oxygen and nitrogen in the products of combustion is not equally well known. Some rough measurements made under essentially the same experimental conditions ${ }^{10}$ indicate a partial deviation of 0.0004 ; and if this is accepted, 1 volume of sample is equivalent to 1.1679 volumes of $\mathrm{CO}_{2}$ in the products of combustion. On the other hand, the conventional assumption, that the deviation of $\mathrm{CO}_{2}$ is proportional to its partial pressure, would fix the partial deviation as 0.0030 , and the corresponding relation would be altered, 1 volume of sample now being equivalent to 1.1709 volumes of $\mathrm{CO}_{2}$ after combustion. The two heating values calculated from these two stoichiometric relations are

$$
\begin{aligned}
& (940.95)(1.1679)=1,099 \mathrm{Btu} / \mathrm{ft}^{3}(1,100)^{11} \\
& (940.95)(1.1709)=1,102 \mathrm{Btu} / \mathrm{ft}^{3}(1,103)
\end{aligned}
$$

Thus the uncertainty in the deviation of $\mathrm{CO}_{2}$ from ideality corresponds to $3 \mathrm{Btu}$, whereas the uncertainty in the stoichiometric determination itself was only $0.7 \mathrm{Btu} / \mathrm{ft}^{3}$, and the uncertainty in the determination of the heat of combustion was

\footnotetext{
10 Joseph R. Branham and Martin Shepherd, Gasometric method and apparatus for the analysis of mixtures of ethylene oxide and carbon dioxide, J. Research NBS 22, 171 (1939) RP1175. (See p. 185.) Joseph R. Branham, Martin Shepherd, and Shuford Schuhmann, Critical study of the determination of carbon monoxide by combustion over platinum in the presence of excessoxygen, J. Research NBS 26,571 (1941) RP1396. (See p. 586.)

11 See footnote “a," p. 30. Parenthetical values given hereafter refer to this same footriote.
}

reported by Rossini as the equivalent of 0.2 $\mathrm{Btu} / \mathrm{ft}^{3}$.

An attempt was made to take advantage of the accuracy of the determination of the heat of combustion by a gravimetric measurement of the $\mathrm{CO}_{2}$ present after the combustion of a known volume of the sample. A number of such determinations were made by E. C. Creitz, of the National Bureau of Standards. The heating values calculated from these determinations and the measured heat of combustion were
Btu/ft ${ }^{3}$
1101.7
1100.3
1101.7
1101.6
1100.7
1099.4
1104.2
1104.1
1102.3
1103.0
$1101.9 \pm 1.2(1102.8)$

Several determinations obviously out of line, and all much lower, have been omitted from this average. There was no direct evidence that all of the gas had always been burned. However, some support is given the value $1,102(1,103) \mathrm{Btu} / \mathrm{ft}^{3}$, derived from the stoichiometric experiment. These values are within 1 Btu of the average determinations with the Junkers calorimeter. ${ }^{12}$

For the present, the average heating value, $1,103 \pm 4 \mathrm{Btu}(1,105)$, obtained with the Junkers instrument will be accepted for comparison with the analyses. This value is noted in the two frequency-distribution plots that give the data for heating values calculated from analyses. All the data are plotted to the nearest $2 \mathrm{Btu} / \mathrm{ft}^{3}$ in figure 12. The greatest frequency is noted at $1,104 \mathrm{Btu}$. The data are plotted to the nearest 1 Btu in figure 13 , with 25 values (8 percent of those reported) omitted. Section $B$ of this plot gives the values calculated from analyses performed by method $B$. These values are more closely grouped than the whole and are higher.

\footnotetext{
12 A standard sample of this type for the cooperative determination of heating value, using the procedure given in the new tentative standard proposed by Subcommittee D-3-III of ASTM on Determination of Calorific Value of Gaseous Fuels, might well be distributed. It would then be possible to compare the reproducibility of the measured heating value with that calculated from analysis. Another profitable excursion would be the accurate determination of heating value, either by improving the gravimetric measurement of carbon dioxide present after combustion, or by means of a more accurate calorimeter.
} 


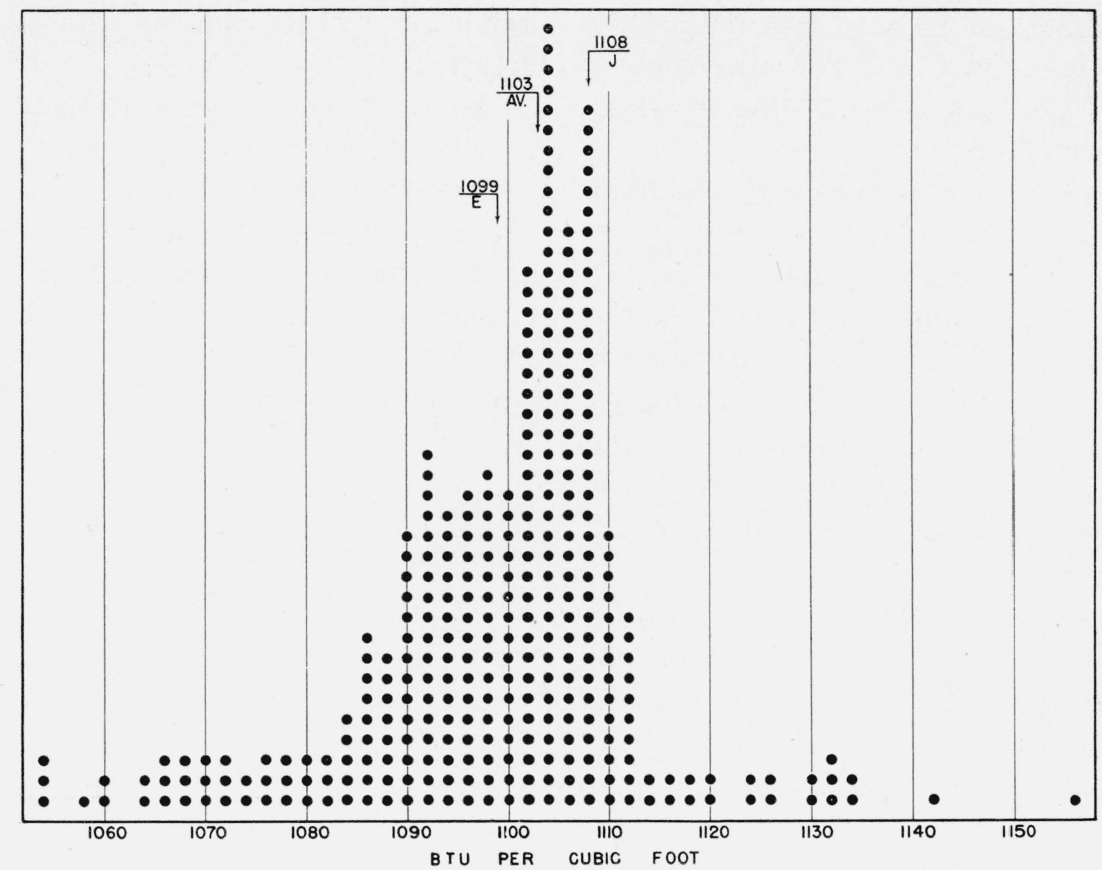

Figure 12.-Frequency-distribution plot for calculated heating value-2.0 Btu interval.

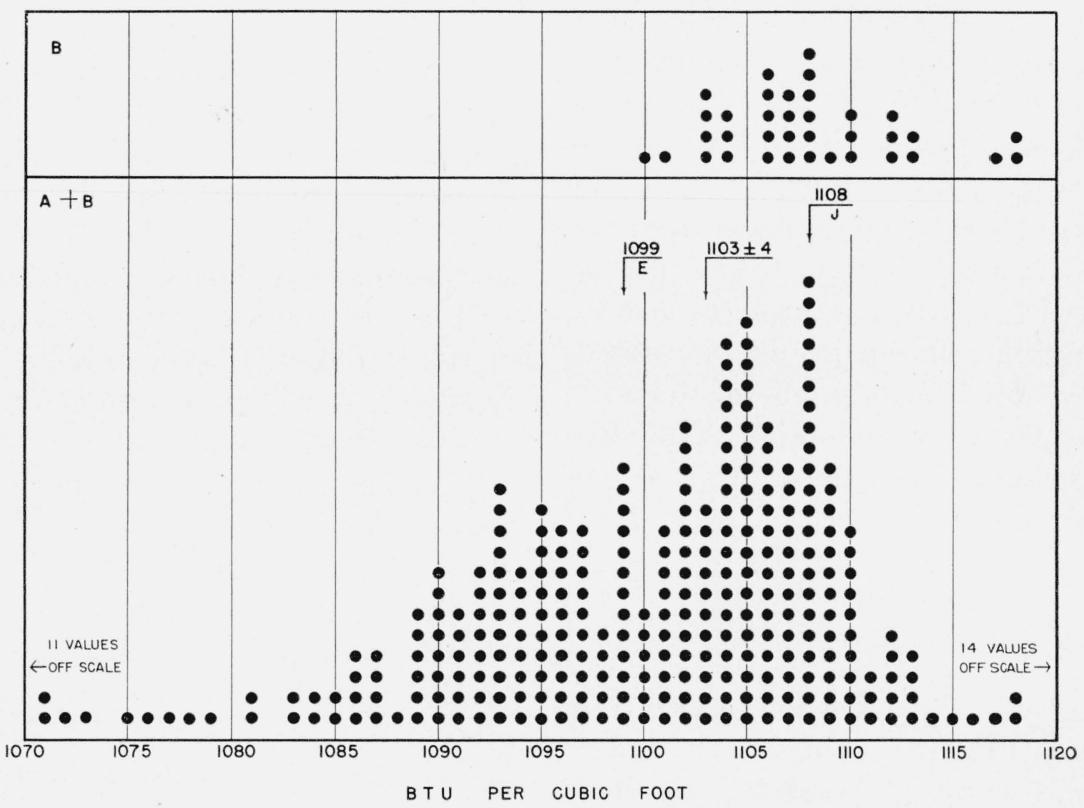

FIGURE 13.-Frequency-distribution plot for calculated heating value-1.0 Btu interval.

The average of the $B$ group is $1,108 \mathrm{Btu} / \mathrm{ft}^{3}$. The average of all the computed values taken from 1,086 to $1,113 \mathrm{Btu}$ (about 85 percent of all values reported) is $1,101 \mathrm{Btu} / \mathrm{ft}^{3}$. These averages for the calculated values are within 0.5 and 0.2 percent, respectively, of the average measured value, which is itself expressed within \pm 0.4 percent. The thing desired of the calculated values is a greater frequency at and near the true heating value. The thing desired of the measured value is a closer approach to whatever the true value may be. 


\section{Laboratory Averages}

So far the picture has included all of the determinations made by all of the laboratories. A picture of each laboratory with relation to the others may now be presented. Figure 14 is a plot showing the average values obtained by each laboratory for each of the constituents determined. Several of the laboratories reported more than one average value, and these have been included as separate points on the plots. Points with a slight tail to the right indicate average values derived from method $B$. All others were derived from too wide, and a need for standardization is indicated.

The average calculated specific gravities and heating values reported by weach laboratory are plotted in figure 15. All values reported are given in the lower sections, marked $A+B+C$. As before, the sections marked $B$ give values obtained by the laboratories using method B. The section marked $C$ gives the results of the laboratories which reported no oxygen in the sample. Apparently there is no correlation between "no oxygen" and calculated specific gravity. However, those who found no oxygen reported

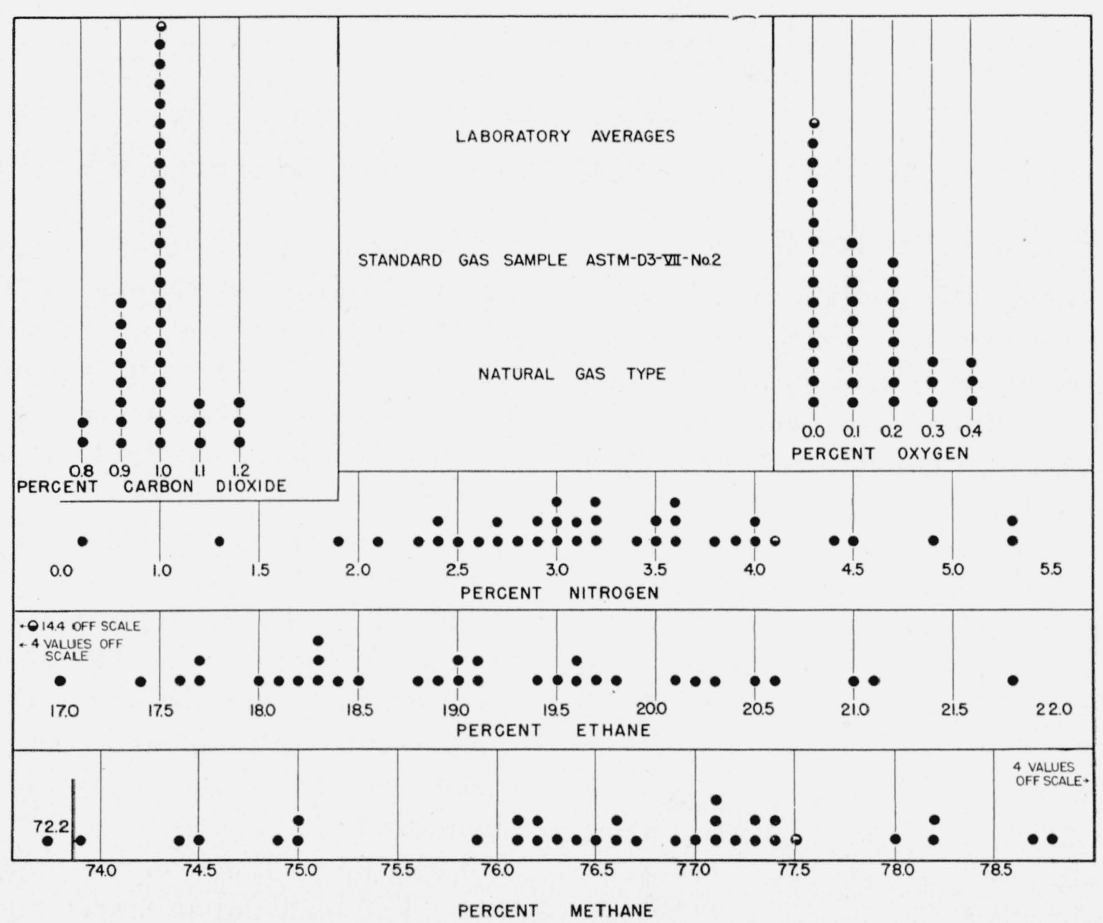

FIGU RE 14.-Frequency-distribution plot for laboratory averages of all constituents.

method $A$, with the very few exceptions to be noted in the next section of this report, which will give results obtained by the three special methods previously noted.

The plot for methane has not included four values higher than 78.8 percent, and that for ethane has omitted four values lower than 17.0 percent. In general, the spread of the averages is heating values which were more consistently grouped around the measured value. This suggests the removal of some hydrocarbons during the absorption analysis, and again the inclusion of some air in the samples transferred for analysisan effect seen in the tendency for these values to wander to the left of center, in comparison with the $\mathrm{C}$ group. 


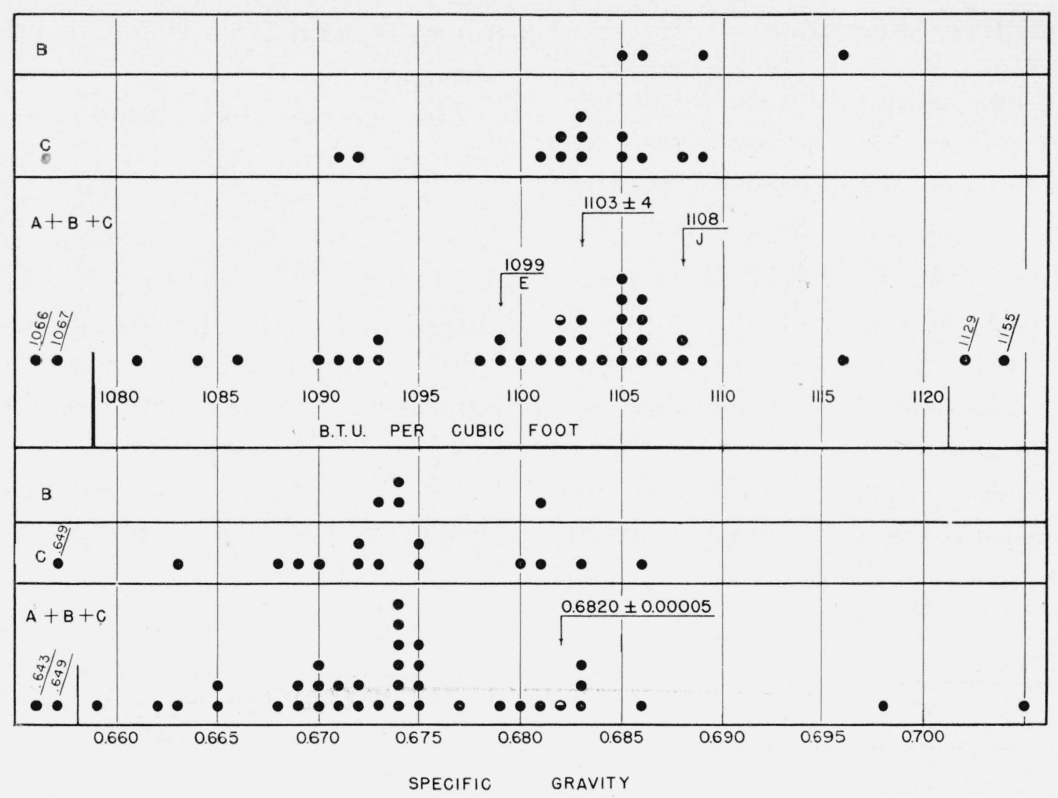

FIGURE 15.-Frequency-distribution plot for laboratory averages of calculated specific gravity and heating value.

\section{Analysis by Method II}

As previously stated, this method is ordinarily used for the analysis of a carburetted-water gas and involves an absorption of unsaturated hydrocarbons in fuming sulfuric acid, as well as a fractional combustion over copper oxide preceding the combustion over the platinum catalyst in the presence of excess oxygen.

Laboratory 21 used this method and reported the following average results:

\begin{tabular}{|c|c|}
\hline 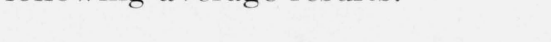 & Percent \\
\hline $\mathrm{CO}_{2 \ldots} \ldots$ & 1. 0 \\
\hline $\mathrm{O}_{2-\ldots}$ & 0. 0 \\
\hline $\mathrm{N}_{2 \ldots \ldots \ldots} \ldots \ldots \ldots \ldots \ldots$ & 5. 3 \\
\hline $\mathrm{C}_{2} \mathrm{H}_{4} \ldots \ldots$ & 0. 6 \\
\hline $\mathrm{H}_{2} \ldots \ldots \ldots$ & 0.5 \\
\hline $\mathrm{C}_{0 \ldots \ldots \ldots \ldots \ldots \ldots} \ldots \ldots \ldots \ldots$ & 0.5 \\
\hline $\mathrm{CH}_{4} \ldots \ldots \ldots$ & 74.5 \\
\hline $\mathrm{C}_{2} \mathrm{H}_{6 \ldots} \ldots$ & 17. 6 \\
\hline Specific gravity & 0.6754 \\
\hline $\mathrm{Btu} / \mathrm{ft}^{3}{ }^{2} \ldots \ldots$ & 1. 065.9 \\
\hline
\end{tabular}

The analysis is interesting for many reasons. The $\mathrm{CO}_{2}$ and $\mathrm{O}_{2}$ are correctly reported. The high nitrogen is not explained by air contamination, and probably resulted from incomplete combustion or a faulty exchange of atmospheric inerts in the reaction tubes.

The amount of $\mathrm{C}_{2} \mathrm{H}_{4}$ found was high, and indicated loss of other constituents in the fuming sulfuric acid. Actually, there was about 0.2 percent of propylene in this sample. Laboratory
1 determined unsaturated compounds by absorption in 10 drops of fuming sulfuric acid on glass wool, using as part of the volumetric apparatus a reaction tube described by Shepherd. ${ }^{13}$ The average of six determinations was $0.19 \pm 0.04$. This was checked later by the mass spectrometer (see following section "Analysis by Mass Spectrometer" of this paper), which indicated the presence of .0 .18 percent of $\mathrm{C}_{3} \mathrm{H}_{6}$ as the only unsaturate present.

The $\mathrm{H}_{2}$ and $\mathrm{CO}$ reported were actually not present in the sample. The absence of hydrogen was definitely established by a separation at the temperature of liquid hydrogen. The absence of carbon monoxide was established by a sensitive chemical test. ${ }^{14}$

Both the methane and ethane found were too low. The calculated specific gravity was low. The calculated heating value, however, was the minimum noted for the whole group, $37 \mathrm{Btu}$ lower than the average measured value.

These results taken alone afford no recommendation for the double combustion method. On the contrary, this refinement of the single combustion method has not yielded the desired results.

Laboratory 24 did not follow method II but did make an absorption in fuming sulfuric acid,

${ }^{13}$ Modification of apparatus for volumetric gas analysis, J. Research NBS 26, 351 (1941) RP1382. See page 354, figure 2, tube number 2.

${ }_{14}$ Martin Shepherd, A preliminary report on the NBS colorimetric indicating gel for the rapid determination of small amounts of carbon monoxide, Anal. Chem. 19, 77 (1947). 
reporting the contraction as $\mathrm{C}_{3} \mathrm{H}_{8}$. The averages found for two series of 10 analyses each were 0.6 and 0.5 percent. The complete results follow:

\begin{tabular}{|c|c|c|}
\hline & $\begin{array}{c}\text { Series } 1 \\
\text { Percent }\end{array}$ & $\begin{array}{c}\text { Series } 2 \\
\text { Percent }\end{array}$ \\
\hline - & 1. 0 & 1. 0 \\
\hline $\mathrm{O}_{2} \ldots \ldots \ldots \ldots \ldots \ldots$ & 0.0 & 0.0 \\
\hline $\mathrm{CH}_{4} \ldots \ldots \ldots \ldots$ & 76.7 & 77. 3 \\
\hline $\mathrm{C}_{2} \mathrm{H}_{6 \ldots} \ldots$ & 18.5 & 18. 1 \\
\hline 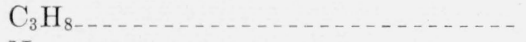 & 0.6 & 0.5 \\
\hline $\mathrm{N}_{2-\ldots \ldots \ldots \ldots \ldots}$ & 3. 2 & 3. 1 \\
\hline gravity _............ & 0.675 & 0.672 \\
\hline $\mathrm{Btu} / \mathrm{ft}^{3}{ }^{3} \ldots \ldots$ & 1106 & 1103 \\
\hline
\end{tabular}

Correct values for $\mathrm{CO}_{2}$ and $\mathrm{O}_{2}$ are reported. The $\mathrm{C}_{2} \mathrm{H}_{6}$ is apparently lowered at the expense of the " $\mathrm{C}_{3} \mathrm{H}_{8}$." The specific gravities are a bit low, but the heating values are very good.

\section{Analysis by Distillation Methods $X$ and $Y$}

Laboratory 28 analyzed the sample by method $A$, but in addition separated the sample by fractional distillation and noted in a secondary report the result of the correction for propane found by the distillation method. The data are

\begin{tabular}{|c|c|c|}
\hline & $\begin{array}{c}\text { A verage values } \\
\text { by method } A\end{array}$ & $\begin{array}{c}\text { Average values } \\
\text { by Method } A \\
\text { corrected for } \\
\mathrm{C}_{3} \mathrm{H}_{8}\end{array}$ \\
\hline$\ldots \ldots \ldots$ & 1. 05 & 1. 05 \\
\hline 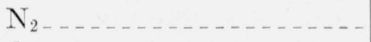 & 3. 95 & 3. 95 \\
\hline _. & 0.05 & 0.05 \\
\hline $\mathrm{CH}_{4} \ldots \ldots \ldots$ & 74. 40 & 77.55 \\
\hline $\mathrm{C}_{2} \mathrm{H}_{6} \ldots \ldots \ldots$ & 20.55 & 14. 25 \\
\hline $\mathrm{C}_{3} \mathrm{H}_{8} \ldots \ldots \ldots \ldots$ & 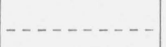 & 3. 15 \\
\hline Specific gravity _........ & 0. 683 & $0.683_{7}$ \\
\hline $\mathrm{Btu} / \mathrm{ft}^{3}$ & 1103.0 & 1103.8 \\
\hline
\end{tabular}

This is very satisfactory work. The slight corrections applied did not materially alter the calculated specific gravity or heating value and did not improve the calculated specific gravity.

Laboratory 29 employed method $X$. The combustion data were thus not calculated as such but corrected for $\mathrm{C}_{3} \mathrm{H}_{8}$ found by fractional distillation. The average values obtained by this laboratory are

$\begin{array}{lc} & \text { Percent } \\ \mathrm{CO}_{2} & 0.8 \\ \mathrm{O}_{2} & .24\end{array}$

Percent

$\mathrm{CH}_{4}$

76. 98

$\mathrm{C}_{2} \mathrm{H}_{6}$

14. 1

$\mathrm{C}_{3} \mathrm{H}_{8}$

3. 0

$\mathrm{N}_{2}$

4. 88

Specific gravity

0. 6838

$\mathrm{Btu} / \mathrm{ft}^{3}$

1091. 6

Carbon dioxide is a bit too low, oxygen is high, and nitrogen is higher than the average value by a large enough amount to suggest air contamination. The calculated heating value is low. The calculated specific gravity is within 0.002 of the measured value. The method should have improved the accuracy of the calculated heating value, and did not.

Laboratory 30 employed method $Y$, which depended upon distillation for all constituents except $\mathrm{CO}_{2}$ and $\mathrm{O}_{2}$. These average results were reported:

\begin{tabular}{|c|c|}
\hline & Percent \\
\hline $\mathrm{CO}_{2-}$ & 1. 00 \\
\hline $\mathrm{O}_{2-}$ & 0.00 \\
\hline $\mathrm{CH}_{4-}$ & 80.6 \\
\hline $\mathrm{C}_{2} \mathrm{H}_{6-}$ & 14. 8 \\
\hline $\mathrm{C}_{3} \mathrm{H}_{8-}$ & ฉ 3.6 \\
\hline $\mathrm{N}_{2-}$ & 0.0 \\
\hline
\end{tabular}

a Actually, the distillation indicated 2.4 percent heavier than $\mathrm{C}_{3} \mathrm{H}_{8}$, but this was called $\mathrm{C}_{3} \mathrm{H}_{8}$ in the computation of specific gravity and heating value.

The distillation method has long been favored over the combustion method for the analysis of natural gases, and it is well understood that the latter method cannot yield the true composition. It is accordingly surprising to find the maximum calculated heating value of the present series of analyses has been derived from the distillation procedure. This heating value is about $50 \mathrm{Btu} / \mathrm{ft}^{3}$ too high. The specific gravity is 0.008 too low. The absorption analysis has reported the correct values for carbon dioxide and oxygen.

\section{Analysis by Mass Spectrometer}

The first two analyses by the Consolidated mass spectrometer were made under the direction of A. Keith Brewer. Notable amounts of hydrogen were reported, and the results were not concordant. The calculated heating value and specific gravity were not in agreement with the measured values 
for the first analysis, but in good agreement in case of the second analysis.

Because of the apparent presence of hydrogen, which is not to be expected in a natural gas in anything like the amount found, a separation of this sample was made at the temperature of liquid hydrogen. This experiment definitely proved the absence of hydrogen (i. e., the amount present could not have exceeded 0.001 percent). Accordingly, the original fragmentation patterns of the hydrocarbons used in the analyses by mass spectrometer were redetermined, and the corrected patterns were then used in computing the mass spectrogram obtained in a third analysis. This analysis and computation were made by Vernon Dibeler. The three analyses are

\begin{tabular}{|c|c|c|c|}
\hline & $\begin{array}{c}\text { First } \\
\text { analysis }\end{array}$ & $\begin{array}{l}\text { Second } \\
\text { analysis }\end{array}$ & $\begin{array}{l}\text { Third } \\
\text { analysis }\end{array}$ \\
\hline $\mathrm{H}_{2 \sim}$ & $\begin{array}{c}\text { Percent } \\
0.34\end{array}$ & $\begin{array}{c}\text { Percent } \\
0.74\end{array}$ & $\begin{array}{l}\text { Percent } \\
0\end{array}$ \\
\hline $\mathrm{CH}_{4-}$ & 68. 02 & 76. 7 & 77.5 \\
\hline $\mathrm{N}_{2-\ldots}$ & 13. 93 & 3. 90 & 4. 09 \\
\hline $\mathrm{C}_{2} \mathrm{H}_{6--}$ & 12.55 & 14. 7 & 14. 4 \\
\hline $\mathrm{C}_{3} \mathrm{H}_{6 \ldots} \ldots$ & 0.22 & 0.17 & 0.18 \\
\hline $\mathrm{CO}_{2} \ldots \ldots$ & 1. 22 & .94 & .96 \\
\hline $\mathrm{C}_{3} \mathrm{H}_{8} \ldots \ldots \ldots$ & 2. 72 & 2. 90 & 2. 82 \\
\hline Other hydrocarbons & 0 & 0 & 0 \\
\hline Specific gravity ....... & 0.719 & 0.680 & 0.682 \\
\hline $\mathrm{Btu} / \mathrm{ft}^{3} \ldots$ & 992 & 1,102 & 1,102 \\
\hline
\end{tabular}

Although the first analysis is out of line, the second and third are in good agreement (with $\mathrm{H}_{2}$ dropped from the second), and both yield excellent values for specific gravity and heating value. The $\mathrm{C}_{3} \mathrm{H}_{6}$ found checks the chemical determination of unsaturated hydrocarbons made by laboratory 1 . The correct value for $\mathrm{CO}_{2}$ was reported, and no oxygen was found. The nitrogen is somewhat higher than the value indicated by chemical analysis. The 2.82 percent of $\mathrm{C}_{3} \mathrm{H}_{8}$ found compares reasonably with the values $3.0,3.1$, and 3.6 , reported by three laboratories using distillation. For ready comparison, the values obtained by the mass spectrometer (third analysis) are plotted in figures 14 and 15 as open circles. Methane and ethane are not directly comparable to the amounts found by combustion; and the propane and propylene do not appear.

\section{Errors in Calculated Specific Gravity and Heating Value}

In view of the additional data furnished by the special methods just discussed, it will be well to reexamine the specific gravity and heating values calculated from the analyses. The presence of 3.0 percent of $\mathrm{C}_{3} \mathrm{H}_{8}$ and 0.2 percent $\mathrm{C}_{3} \mathrm{H}_{6}$ in this sample seems well established. (The figures have been rounded off to the needed significance.) As these $\mathrm{C}_{3}$ hydrocarbons were computed as $\mathrm{CH}_{4}$ and $\mathrm{C}_{2} \mathrm{H}_{6}$, it is well to check the errors thus introduced in the calculated values.

Propane is calculated thus in the analysis:

$$
\mathrm{C}_{3} \mathrm{H}_{8} \rightarrow 2 \mathrm{C}_{2} \mathrm{H}_{6}-\mathrm{CH}_{4} \text {. }
$$

Accordingly, the calculated specific gravity was too high by 0.002 :

$$
1.5624 \rightarrow 2(1.0493)-0.5544
$$

$(0.03)(1.6442$ calculated -1.5624 actual $)=0.0024$

Similarly, the calculated heating value was too low by $0.2 \mathrm{Btu} / \mathrm{ft}^{3}$ :

$$
\begin{gathered}
2528 \rightarrow 2(1759)-997 \\
0.03(2528-2521)=0.21 .
\end{gathered}
$$

The calculation for the propylene depends in turn on the manner in which methane and ethane were calculated.

(1) When $\mathrm{CH}_{4}$ and $\mathrm{C}_{2} \mathrm{H}_{6}$ are calculated from total contraction and carbon dioxide formed, these stoichiometric relations are used:

$$
\begin{aligned}
& \mathrm{CH}_{4}=1 / 3\left(4 T C-5 \mathrm{CO}_{2}\right) \\
& \mathrm{C}_{2} \mathrm{H}_{6}=1 / 3\left(4 \mathrm{CO}_{2}-2 T C\right) .
\end{aligned}
$$

With propylene injected, $T C$ and $\mathrm{CO}_{2}$ are expressed thus:

$$
\begin{aligned}
T C & =2 \mathrm{CH}_{4}+2.5 \mathrm{C}_{2} \mathrm{H}_{6}+2.5 \mathrm{C}_{3} \mathrm{H}_{6} \\
\mathrm{CO}_{2} & =\mathrm{CH}_{4}+2 \mathrm{C}_{2} \mathrm{H}_{6}+3 \mathrm{C}_{3} \mathrm{H}_{6} .
\end{aligned}
$$

Accordingly, $\mathrm{CH}_{4}$ and $\mathrm{C}_{2} \mathrm{H}_{6}$, calculated as above, are in error:

$$
\begin{aligned}
\mathrm{CH}_{4} & \rightarrow \mathrm{CH}_{4}-5 / 3 \mathrm{C}_{3} \mathrm{H}_{6} \\
\mathrm{C}_{2} \mathrm{H}_{6} & \rightarrow \mathrm{C}_{2} \mathrm{H}_{6}+7 / 3 \mathrm{C}_{3} \mathrm{H}_{6} .
\end{aligned}
$$

The 0.2-percent propylene thus makes the calculated $\mathrm{CH}_{4}$ too low by $(5 / 3)(0.2)=0.33$, and the $\mathrm{C}_{2} \mathrm{H}_{6}$ too high by $(7 / 3)(0.2)=0.47$ percent. 
(2) Similarly, when $\mathrm{CH}_{4}$ and $\mathrm{C}_{2} \mathrm{H}_{3}$ are calculated from the total contraction plus carbon dioxide and the oxygen consumed, according to the relations

$$
\begin{aligned}
\mathrm{CH}_{4} & =1 / 3\left[7\left(7 \mathrm{C}+\mathrm{CO}_{2}\right)-9 \mathrm{O}_{2}\right] \\
\mathrm{C}_{2} \mathrm{H}_{6} & =1 / 3\left[6 \mathrm{O}_{2}-4\left(\mathrm{TC}+\mathrm{CO}_{2}\right)\right],
\end{aligned}
$$

and the $\left(\mathrm{TC}+\mathrm{CO}_{2}\right)$ and $\mathrm{O}_{2}$ are expressed

$$
\begin{aligned}
\left(T C+\mathrm{CO}_{2}\right) & \rightarrow 3 \mathrm{CH}_{4}+4.5 \mathrm{C}_{2} \mathrm{H}_{6}+5.5 \mathrm{C}_{3} \mathrm{H}_{6} \\
\mathrm{O}_{2} & \rightarrow 2 \mathrm{CH}_{4}+3.5 \mathrm{C}_{2} \mathrm{H}_{6}+4.5 \mathrm{C}_{3} \mathrm{H}_{6},
\end{aligned}
$$

the calculated $\mathrm{CH}_{4}$ and $\mathrm{C}_{2} \mathrm{H}_{3}$ are in error thus:

$\mathrm{CH}_{4} \rightarrow \mathrm{CH}_{4}-2 / 3 \mathrm{C}_{3} \mathrm{H}_{6}=0.13$ percent (in this case) $\mathrm{C}_{2} \mathrm{H}_{6} \rightarrow \mathrm{C}_{2} \mathrm{H}_{6}+5 / 3 \mathrm{C}_{3} \mathrm{H}_{6}=0.33$ percent (in this case).

The errors can now be evaluated:

(1) When $\mathrm{CH}_{4}$ and $\mathrm{C}_{2} \mathrm{H}_{6}$ are calculated from $T C$ and $\mathrm{CO}_{2}$ alone, the presence of 0.2 percent of $\mathrm{C}_{3} \mathrm{H}_{6}$ causes the calculated specific gravity to be too high by 0.0002 (which is not significant): $(0.0047)(1.049)-(0.0033)(0.5544)-0.002(1.45)=$ 0.0002 .

The calculated heating value is $0.3 \mathrm{Btu} / \mathrm{ft}^{3}$ too high: (0.0047) (1759) - (0.0033) (997.4) - (0.002) (2339).

(2) When $\mathrm{CH}_{4}$ and $\mathrm{C}_{2} \mathrm{H}_{6}$ are calculated from $\left(\mathrm{TC}+\mathrm{CO}_{2}\right)$ and $\mathrm{O}_{2}, 0.2$ percent of $\mathrm{C}_{3} \mathrm{H}_{6}$ makes the calculated specific gravity too low by 0.001 (not significant): (0.002) (1.45) - [(0.0033) (1.049) (0.0013) (0.5544)] and the calculated heating value too low by $0.2 \mathrm{Btu} / \mathrm{ft}^{3}$ : (0.002) (2339) - [(0.0033) (1759) - (0.0013) (997.4)].

The errors for propane and propylene may now be combined:

(1) The calculation from $\mathrm{TC}$ and $\mathrm{CO}_{2}$ makes the calculated specific gravity too high by 0.002 , and the calculated heating value too high by 0.1 $\mathrm{Btu} / \mathrm{ft}^{3}$.

(2) The calculation from $\left(\mathrm{TC}+\mathrm{CO}_{2}\right)$ and $\mathrm{O}_{2}$ makes the calculated specific gravity too high by 0.002 and the calculated heating value too low by $0.4 \mathrm{Btu} / \mathrm{ft}^{3}$.

The errors in calculated heating value are of no interest, once they are known. The error in specific gravity does not improve the situation, since the correction would move the calculated value further from the observed one.

\section{Comparison of Analysts in Same Laboratory}

The extent to which the different analysts using the same apparatus and method will achieve concordant results has often been discussed and with varying opinions. One school holds that analysts are born and not made; while a second and more optimistic group believe that any high-school child can be quickly converted to the desired robot. The analyses submitted in this cooperative series prove nothing conclusively, but offer interesting comparisons to show that analysts using the same apparatus and procedure can be together or apart, which was to be expected.

Two frequency distribution plots have been prepared to give this picture. It was not worthwhile to plot each component of the mixture. Nitrogen and the calculated heating value were selected to illustrate these agreements and disagreements; nitrogen because it is a measure of the over-all behavior of the chemical analysis, and is comparable no matter what procedure has been used; and heating value because it is another measure of the over-all success of the analysis, and of especial engineering interest.

The plots showing the comparative results of analyst versus analyst are shown in figures 16 and 17. Each laboratory that contributed to this competition is numbered and separated by heavy horizontal boundaries. The analysts who entered each laboratory competition are lettered, and their individual efforts are separated by lighter horizontal boundaries.

By reading these plots we find, for example, that analysts $A$ and $D$ in laboratory 2 were on good terms. Figure 16 for nitrogen shows no evidence for great concern until laboratories 22 and 23 are examined. It is obvious that in both laboratories an analyst, $M$, had some difficulty in deciding upon a suitable value. Figure 17 shows in general a somewhat greater disagreement. There are differences between analysts $A$ and $B$ of laboratory $5, A$ and $B$ of laboratory 14 , and $M$ and $N$ of laboratory 22, which might well be straightened out. Laboratories 2, 17, 18, 20, and 24 appear to have arrived at agreement with themselves if not always with each other. Here then is a brief picture showing the expected differences in talent. 


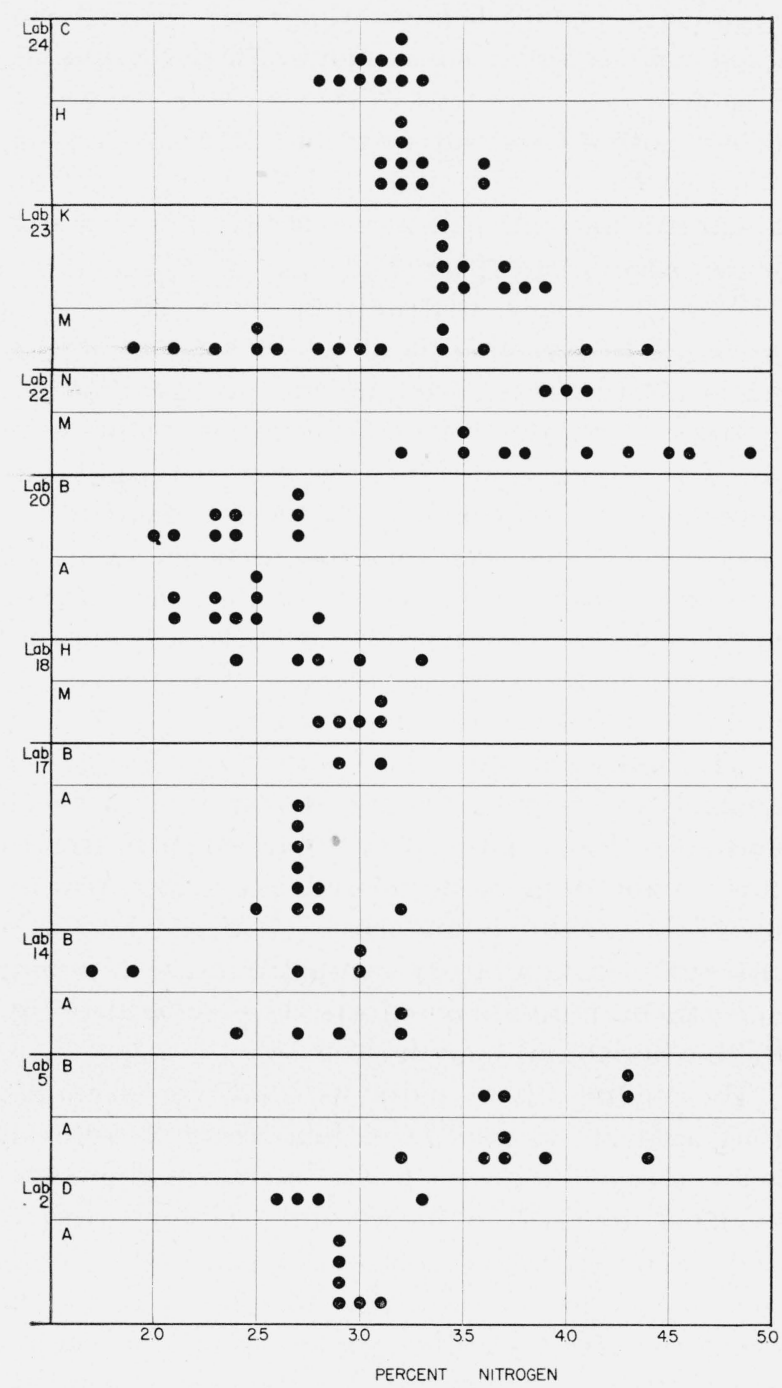

FIGURE 16.-Frequency-distribution plot comparing different analysts in the same laboratory with percent nitrogen as the basis for comparison.

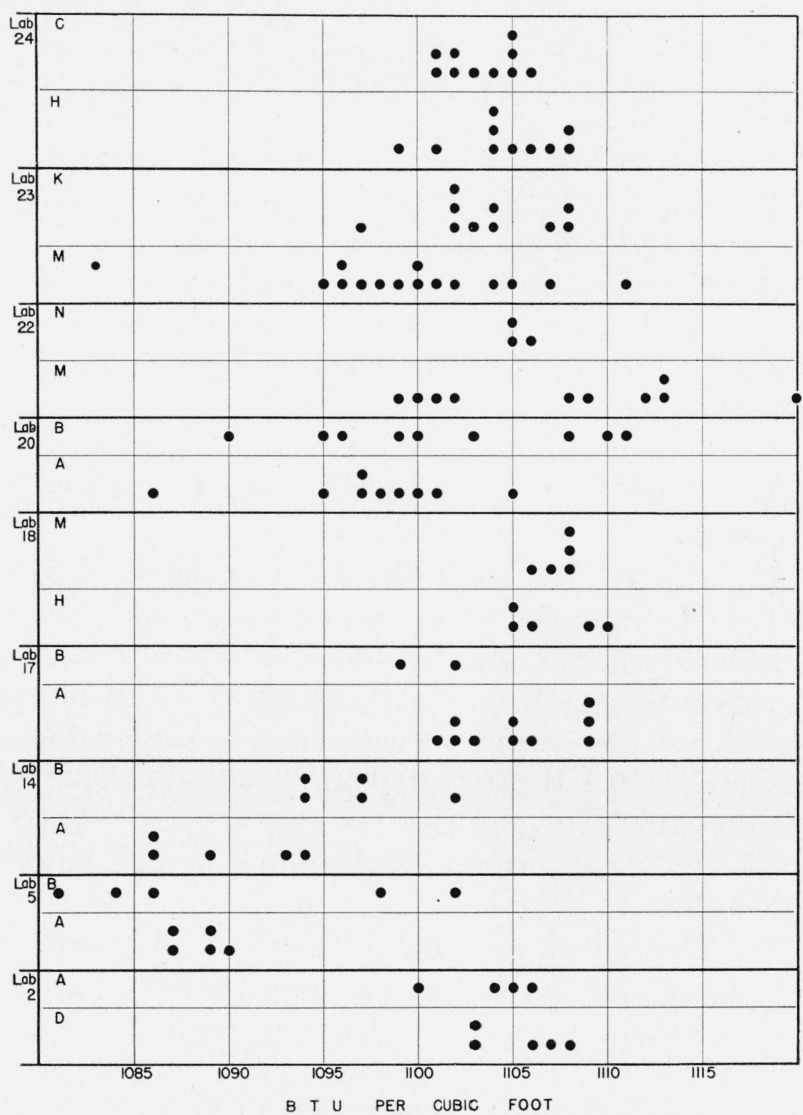

FIGURE 17.-Frequency-distribution plot comparing different analysts in the same laboratory, with calculated heating value as the basis for comparison. 


\section{Comparison of Laboratories Within Same Organization}

It might logically be expected that laboratories within th esame organization would have compared results and composed their differences, but the story seems to be much the same as for the individual analysts. The data available offer no other information than this, for their number is not sufficient to tempt a statistical statement as to the proportion of agreement and disagreement within companies.

These data, again for nitrogen and heating value, have been plotted in figures 18 and 19 .

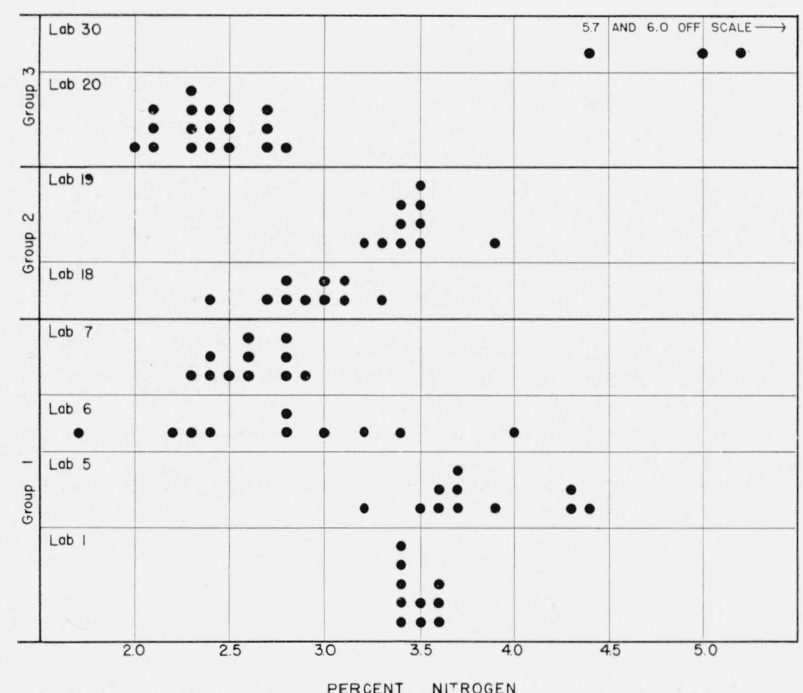

Figure 18.-Frequency-distribution plot comparing different laboratories in the same organization, with percent nitrogen as the basis for comparison.

There are three groups or organizations represented, divided on the plots by heavy horizontal boundaries; the laboratories within each group are separated by lighter horizontal boundaries.

Perhaps there is less reason to expect agreement among the four laboratories in group 1 than in the other two cases, for this is a group of Government laboratories. Laboratories 5, 6, and 7 are in the same Bureau, and 5 and 6 are in the same building; but each laboratory employs different apparatus and methods. Laboratory 1 is in another Bureau. The agreement between laboratories 1 and 5 in the matter of percentage of nitrogen is not extended to laboratories 6 and 7 . The agreement between laboratories 1 and 7 in the calculated heating value is not extended to laboratories 5 and 6 .

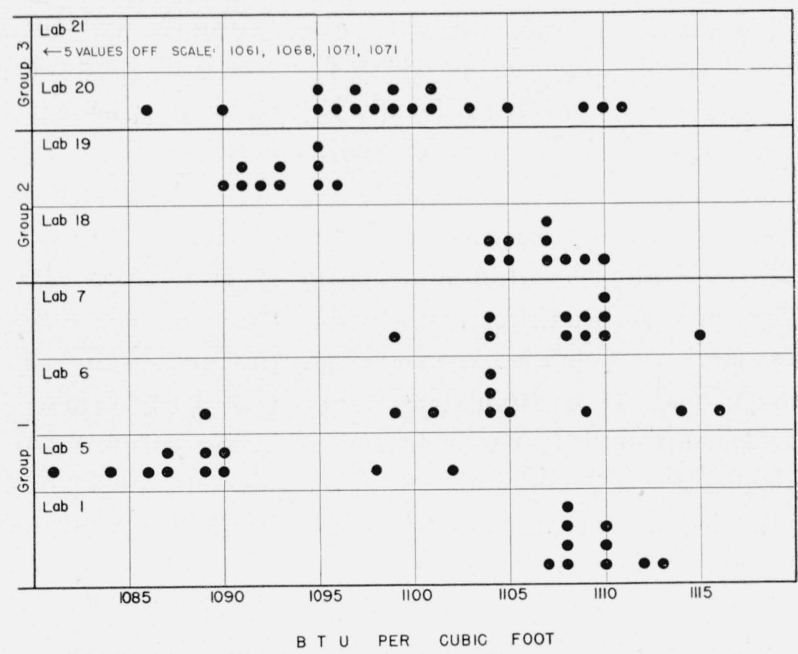

Figure 19.-Frequency-distribution plot comparing different laboratories in the same organization, with computed heating value as the basis for comparison.

In the case of laboratories 18 and 19 of group 2 , both in the same company, and both operating in connection with different phases of the same general project and in the same location, there is only fair agreement on the percentage of nitrogen, and no good agreement on heating value. Both laboratories employed like apparatus and methods. In the case of laboratories 20 and 21 of group 3, both laboratories were in the same company, but were widely separated geographically, and used different methods. There is no agreement between these laboratories. Indeed, it was not found possible to plot the results of laboratory 21 on the scale selected to include the other laboratories.

These cases pictured in the last four plots serve to emphasize the need for standardization, and the further need for equally expert analysts.

\section{Conclusions}

The data presented here give the first clear picture so far available of the actual status of gas analysis of this particular type in this country. As such they are worthy of considerable reflection on the part of gas chemists and plant engineers. In view of the considerable effort expended by everyone who took part in the analyses, and because of the importance of the data, the committee believes that the results should be released for study by all laboratories engaged in this type 
of volumetric gas analysis, even though the data need to be supplemented by further investigation.

Some very creditable work has been presented and some that should have been better. The data indicate a considerable degree of standardization in the use of modern equipment, but, nevertheless, offer evidence to support the claim that further important standardization is certainly needed to clear up the analytical picture, especially with respect to operating technic and methods.

In particular, the relative accuracy and reproducibility of methods $A$ and $B$ herein described should be determined more thoroughly. Further correlation of the results obtained by the absorption-combustion and the distillation methods is an indicated need. An investigation of the accuracy and reproducibility of that important new analytical tool, the mass spectrometer, is another indicated need. And quite aside from the analytical, one or two standard samples might well be distributed to cooperating laboratories for the determination of heating value, using the recently proposed ASTM Tentative Standard. In this connection, the need for a very accurate method to determine heating value is becoming more apparent.

\section{TABLE 1.-Analytical data reported by the cooperating laboratories}

Each laboratory has been assigned a number, and the reports are arranged in the order of these numbers. At the left hand, just under the laboratory number, the method used is designated by the proper key letter. At the right hand, under the laboratory number, is the key designating the apparatus used. These keys are given below.

Referring to the tabulated data, column 1 gives the analysis number, column 2 the analyst, columns $3,4,5,6,7$ give in order the percentage by volume of $\mathrm{CO}_{2}, \mathrm{O}_{2}, \mathrm{CH}_{4}, \mathrm{C}_{2} \mathrm{H}_{6}$, and $\mathrm{N}_{2}$. Column 8 is used to report other hydrocarbons, or other gases, which may have been determined by special methods. Column 9 gives the total for all the constituents determined. Columns 10 and 11 give, respectively, the heating value (in Btu/ft ${ }_{\mathrm{AsTM}}$ ) and specific gravity calculated from the analyses. The measured heating value was $1,103 \pm 4 \mathrm{Btu} / \mathrm{ft}^{3}$ ( $30 \mathrm{in}, \mathrm{Hg}, 60^{\circ} \mathrm{F}$, saturated), and the measured specific gravity was $0.6820=0.00005$, referred to dry $\mathrm{CO}_{2}$-free air

The keys to methods and apparatus follow.

\section{Method A}

1. Absorption of carbon dioxide in an aqueous solution of potassium hydroxide.

2. Absorption of oxygen in alkaline pyrogallol or in a chromous solution.

3. A single combustion over hot platinum in the presence of excess oxygen, measurement of the contraction and carbon dioxide produced, and computation of all hydrocarbons present as $\mathrm{CH}_{4}$ and $\mathrm{C}_{2} \mathrm{H}_{6}$, using the conventional formulas:

$$
\begin{aligned}
\mathrm{CH}_{4} & =1 / 3\left(4 T C-5 \mathrm{CO}_{2}\right) \\
\mathrm{C}_{2} \mathrm{H}_{6} & =1 / 3\left(4 \mathrm{CO}_{2}-2 T C\right),
\end{aligned}
$$

where $T C$ is the total contraction on burning, and $\mathrm{CO}_{2}$ is the carbon dioxide produced by the combustion.

4. Nitrogen by difference.

\section{Method B}

1. Absorption of carbon dioxide in a solution of potassium hydroxide.

2. Absorption of oxygen in alkaline pyrogallol.

(One of the four laboratories then took fresh portions of the sample for combustion, correcting the combustion data for the $\mathrm{CO}_{2}$ and $\mathrm{O}_{2}$ originally found. The other three used the general procedure of combustion of a portion of the sample taken for absorption.)

3. A single combustion over hot platinum in the presence of excess oxygen, measurement of the contraction, carbon dioxide produced, oxygen consumed, and the unreacted residue. Computation of all hydrocarbons as $\mathrm{CH}_{4}$ and $\mathrm{C}_{2} \mathrm{H}_{6}$ using the formulas:

$$
\begin{aligned}
\mathrm{CH}_{4} & =1 / 3\left[7\left(T C+\mathrm{CO}_{2}\right)-9 \mathrm{O}_{2}\right] \\
\mathrm{C}_{2} \mathrm{H}_{6} & =1 / 3\left[6 \mathrm{O}_{2}-4\left(T C+\mathrm{CO}_{2}\right)\right] .
\end{aligned}
$$

4. Nitrogen reported as the measured unreacted residue.

\section{Method X}

1. $\mathrm{CO}_{2}$ and $\mathrm{O}_{2}$ by absorprion in a separate sample.

2. A single combustion of the hydrocarbons, with measurement of con traction and carbon dioxide produced.

3. A separation of the hydrocarbons by distillation in one of the usual rectifying columns.

4. Correction of the combustion data to take account of hyrdocarbons heavier than $\mathrm{C}_{2} \mathrm{H}_{6}$.

\section{Method Y}

1. $\mathrm{CO}_{2}$ and $\mathrm{O}_{2}$ separately by absorption.

2. Other components by distillation.

\section{Apparatus}

$\mathrm{V}_{1}$-Volumes are made comparable by means of a pressure-temperature compensator with manometer interposed between the compensating tube and the burette.

$\mathrm{V}_{2}$ - Pressure within the burette is balanced against existing barometric pressure, and gas volumes are corrected from the observed pressure and temperature to a common bașis, including a correction for changes in the saturation pressure of water.

$\mathrm{V}_{3}$-Pressure in burette is balanced against atmospheric pressure but no correction is made for changes in pressure or temperature during analysis.

$\mathrm{V}_{4}$-Volumes are measured by observing the pressure exerted within a constant volume.

$\mathrm{R}_{1}$-Pipettes are connected to the burette by a manifold.

$\mathrm{R}_{2}-\mathrm{A}$ single pipette, connected to the burette, serves for all reactions.

$\mathrm{R}_{3}$ - Pipettes are temporarily connected in succession to the burette as the different reactions are progressively conducted.

$\mathrm{R}_{4}$-The burette itself serves as a reaction tube.

$\mathrm{Hg}$-Mercury is used as the confining fluid.

$\mathrm{H}_{2} \mathrm{O}$-(with appropriate subscript) - An aqueous solution serves as the confining fluid. 
TABLE 1.-Analytical data reported by the cooperating laboralories-Continued

\begin{tabular}{|c|c|c|c|c|c|c|c|c|c|c|}
\hline \multirow{2}{*}{ Anal. No. } & \multirow{2}{*}{ Analyst } & \multicolumn{7}{|c|}{ Percentage by volume } & \multicolumn{2}{|c|}{ Calculated } \\
\hline & & $\mathrm{CO}_{2}$ & $\mathrm{O}_{2}$ & $\mathrm{CH}_{4}$ & $\mathrm{C}_{2} \mathrm{H}_{6}$ & $\mathrm{~N}_{2}$ & $\left(\mathrm{C}_{\mathrm{n}} \mathrm{H}_{2 \mathrm{n}}\right)$ & Total & $\mathrm{Btu} / \mathrm{ft}^{3}$ & sp gr \\
\hline $1 \ldots$ & Ss & 0.99 & 0.01 & -..... & -..... & -..... & 0.22 & ...... & ......... & -..... \\
\hline $2 \ldots \ldots$ & SS & .96 & .0 .0 & -..... & ........ & -..... & .17 & ...... & ........ & - \\
\hline $3 \ldots$ & SS & .98 & .02 & ........ & - & -...... & .19 & ...... & ....... & - n- \\
\hline $4 \ldots$ & SS & 1.02 & .00 & ........ & - & -...... & .21 & - n & -..... & -....- \\
\hline 5 & SS & 1.00 & -.04 & ........ & - n- & -....- & .20 & -..... & ....... & -....- \\
\hline $6 \ldots \ldots$ & SS & 0.97 & -.01 & -...... & -...... & -....- & .17 & - n. & -...... & -..... \\
\hline 7 & SS & 1.02 & ...... & ........ & - n. & ...... & ....... & ..... & ........ & - \\
\hline $8 \ldots \ldots$ & SS & 1.02 & ..... & -...... & - & -..... & ...... & -.... & ....... & -..... \\
\hline $9 \ldots$ & SS & 1.04 & ...... & ........ & ........ & ....... & ....... & ...... & , & -..... \\
\hline $10 \ldots$ & SS & 1.03 & - & ........ & $\ldots \ldots$ & -..... & -..... & -.... & ....... & ....... \\
\hline Avg.- & $\cdots$ & 1.00 & 0.00 & - & -..... & -..... & 0.19 & - n.... & ...... & -..... \\
\hline $1 \ldots$ & SS & 1.00 & 0.00 & 74.77 & 2088 & 3.36 & 0.19 & 100.01 & 1.113 & 0.682 \\
\hline $2 \ldots$ & SS & 1.00 & $\begin{array}{r}0.00 \\
.00\end{array}$ & 75.06 & $\begin{array}{l}20.00 \\
20.55\end{array}$ & $\begin{array}{l}5.30 \\
3.39\end{array}$ & $\begin{array}{r}0.19 \\
.19\end{array}$ & 100.00 & 1,110 & .680 \\
\hline $3 \ldots$ & SS & 1.00 & .00 & 74.30 & 21.08 & 3.62 & .19 & 100.00 & 1,112 & .684 \\
\hline $4 \ldots \ldots$ & SS & 1.00 & .00 & 75.15 & 20.36 & 3.49 & .19 & 100.00 & 1,108 & .680 \\
\hline $5 \ldots$ & SS & 1.00 & .00 & 75.27 & 20.33 & 3.41 & .19 & 100.01 & 1,108 & .679 \\
\hline $6 \ldots$ & SS & 1.00 & .00 & 74.81 & 20.59 & 3.60 & .19 & 100.00 & 1,108 & .681 \\
\hline $7 \ldots$ & SS & 1.00 & .00 & 75.01 & 20.57 & 3.41 & .19 & 99.99 & 1,110 & .680 \\
\hline $8 \ldots$ & SS & 1.00 & .00 & 75.07 & 20.44 & 3.49 & .19 & 100.00 & 1,108 & .680 \\
\hline $9 \ldots$ & SS & 1.00 & .00 & 75. 03 & 20.38 & 3.59 & 19 & 100.00 & 1,107 & .680 \\
\hline $10 \ldots \ldots$ & SS & 1.00 & .00 & 75.06 & 20.53 & 3.41 & 19 & 100.00 & 1,110 & .680 \\
\hline Arg .. & & & & 74.95 & 20.57 & 3. 48 & & 100.00 & 1,109 & 0.681 \\
\hline
\end{tabular}

\begin{tabular}{|c|c|c|c|c|c|c|c|c|c|c|}
\hline \multirow{2}{*}{ Anal. No. } & \multirow{2}{*}{ Analyst } & \multicolumn{7}{|c|}{ Percentage by volume } & \multicolumn{2}{|c|}{ Calculated } \\
\hline & & $\mathrm{CO}_{2}$ & $\mathrm{O}_{2}$ & $\mathrm{CH}_{4}$ & $\mathrm{C}_{2} \mathrm{H}_{6}$ & $\mathrm{~N}_{2}$ & $\left(\mathrm{C}_{3} \mathrm{H}_{8}\right)$ & Total & $\mathrm{Btu} / \mathrm{ft}^{3}$ & $\mathrm{sp} g \mathrm{r}$ \\
\hline $1 \ldots$ & $\mathrm{D}$ & 1.13 & 0.12 & 76.05 & 19.60 & 3.11 & -..... & 100.01 & 1103. 28 & 0.6761 \\
\hline $2 \ldots$ & $\mathrm{D}$ & 1.13 & .07 & 76.02 & 19.85 & 2. 91 & -.... & 99.98 & 1107.38 & .6762 \\
\hline $3 \ldots$ & $\mathrm{D}$ & 1.15 & .12 & 76.26 & 19.62 & 2.86 & . & 100.01 & 1105.74 & .6754 \\
\hline $4 \ldots \ldots \ldots$ & $\mathrm{D}$ & 1.05 & .05 & 76.24 & 19.75 & 2.92 & -..... & 100.01 & 1107.82 & .6750 \\
\hline $5 \ldots$ & $\mathrm{D}$ & 0.99 & .12 & 76.35 & 19.64 & 2.90 & ....... & 100.00 & 1106.98 & .6740 \\
\hline $6 \ldots \ldots$ & $\mathrm{D}$ & 1.02 & .22 & 76.67 & 19. 26 & 2.84 & & 100.01 & 1103.49 & .6728 \\
\hline $7 \ldots$ & A & 0.89 & .10 & 77. 24 & 18. 96 & 2.82 & ...... & 100.01 & 1103.90 & .6693 \\
\hline $8 \ldots$ & A & 1.08 & .10 & 77.01 & 19. 25 & 2.57 & - & 100.01 & 1107.00 & .6722 \\
\hline $9 \ldots$ & A & 0.98 & .10 & 76.45 & 19. 73 & 2.75 & ...... & 100.01 & 1100.00 & .6736 \\
\hline $10 \ldots \ldots$ & A & .83 & .18 & 75.80 & 19.88 & 3.36 & -.... & 100.05 & 1106.00 & .6762 \\
\hline Avg.. & ...... & 1.03 & 0.12 & 76.41 & 19.55 & 2.90 & -..... & 100.01 & 1106.16 & 0.6741 \\
\hline
\end{tabular}

\begin{tabular}{|c|c|c|c|c|c|c|c|c|c|c|}
\hline $1 \ldots$ & PS & 1.05 & 0.06 & 75.96 & 20.15 & 2.79 & ....... & 100.01 & 1,112 & 0.676 \\
\hline $2 \ldots \ldots \ldots . . . . .$. & PS & 1.07 & .08 & 75.73 & 20.59 & 2.53 & -..... & 100.00 & 1,118 & .678 \\
\hline 3 & PS & 1. 05 & .06 & 75.80 & 20.58 & 2.52 & -..... & 100.01 & 1,118 & .677 \\
\hline 4 & PS & 0.99 & .06 & 76.56 & 19.87 & 2.53 & ...... & 100.01 & 1,113 & .673 \\
\hline $5 \ldots$ & PS & 1. 03 & .08 & 76.45 & 20.14 & 2.31 & ...... & 100.01 & 1,117 & .674 \\
\hline $6 \ldots$ & PS & a 1.02 & a. 02 & 77.69 & 19.82 & 1.47 & -..... & 100.02 & 1,124 & .669 \\
\hline - & PS & a 1.02 & a. 02 & 77.37 & 19.35 & 2.27 & ....... & 100.03 & 1,112 & .670 \\
\hline Avg.... & -.... & 1. 03 & .05 & 76.51 & 20.07 & 2.35 & ...... & ..... & 1,116 & 0.674 \\
\hline
\end{tabular}


TABLE 1.-Analytical data reported by the cooperating laboratories-Continued

Method $R$

LABORATORY NUMBER 4

\begin{tabular}{|c|c|c|c|c|c|c|c|c|c|c|}
\hline \multirow{2}{*}{ Anal. No. } & \multirow{2}{*}{ Analyst } & \multicolumn{7}{|c|}{ Percentage by volume } & \multicolumn{2}{|c|}{ Calculated } \\
\hline & & $\mathrm{CO}_{2}$ & $\mathrm{O}_{2}$ & $\mathrm{CH}_{4}$ & $\mathrm{C}_{2} \mathrm{H}_{6}$ & $\mathrm{~N}_{2}$ & $\left(\mathrm{C}_{3} \mathrm{H}_{8}\right)$ & Total & $\mathrm{Btu} / \mathrm{ft}^{3}$ & $\operatorname{spgr}$ \\
\hline $1 \ldots$ & $\mathrm{sC}$ & 1.02 & 0.00 & 77.09 & 19. 29 & 2.60 & & 100.0 & 1,108 & 0.671 \\
\hline $2 \ldots$ & $\mathrm{SC}$ & 1.02 & .00 & 76. 70 & 19.41 & 2.87 & & 100.0 & 1,106 & 672 \\
\hline $3 \ldots$ & $\mathrm{sC}$ & 1.04 & .00 & 76.31 & 19.80 & 2.85 & 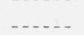 & 100.0 & 1,109 & .674 \\
\hline $4 \ldots$ & $\mathrm{sC}$ & 1.03 & .00 & 77.22 & 18.82 & 2. 93 & & 100.0 & 1,101 & .670 \\
\hline $5 \ldots$ & $\mathrm{SC}$ & 1.04 & .00 & 76.25 & 19. 66 & 3.05 & & 100.0 & 1,106 & .675 \\
\hline $6 \ldots$ & $\mathrm{SC}$ & 1.00 & .00 & 76.63 & 19. 27 & 3.10 & & 100.0 & 1,103 & .672 \\
\hline 7 & $\mathrm{SC}$ & 1.02 & .00 & 76.74 & 19. 18 & 3.06 & ...... & 100.0 & 1,103 & .672 \\
\hline $8 \ldots$ & $\mathrm{sC}$ & 1.05 & .00 & 76.74 & 19. 19 & 3.02 & & 100.0 & 1,103 & .672 \\
\hline $9 \ldots \ldots$ & $\mathrm{sC}$ & 1.00 & .00 & 76.47 & 19.50 & 3. 03 & - & 100.0 & 1,106 & .673 \\
\hline $10 \ldots$ & $\mathrm{SC}$ & 1.01 & .00 & 76.30 & 19.52 & 3.17 & - . & 100.0 & 1,104 & .674 \\
\hline Avg... & ...... & 1.02 & 0.00 & 76.65 & 19.36 & 2.97 & .... & 100.0 & 1,105 & 0.673 \\
\hline
\end{tabular}

Method $A$

LABORATORY NUMBER 5

\begin{tabular}{|c|c|c|c|c|c|c|c|c|c|c|}
\hline $1 \ldots$ & A & 1.1 & 0.2 & 77. 6 & 17.9 & 3. 2 & $\ldots$ & 100.0 & 1,089 & 0.668 \\
\hline $2 \ldots$ & A & 1.0 & .3 & 76.7 & 18.3 & 3.7 & ...... & 100.0 & 1,087 & .672 \\
\hline $3 \ldots$ & A & 1.0 & .3 & 76.6 & 18.5 & 3.6 & ..... & 100.0 & 1,089 & .672 \\
\hline $4 \ldots+\ldots \ldots$ & $\mathrm{A}$ & 1.0 & .1 & 76.7 & 18.5 & 3.7 & & 100.0 & 1,090 & .672 \\
\hline $5 \ldots$ & $\mathrm{B}$ & 1.0 & .1 & 77.0 & 17. 6 & 4.3 & ....... & 100.0 & 1,078 & .670 \\
\hline 6 & B & 1.0 & a 1.4 & 75.6 & 17.9 & ...... & - . & ..... & 1,069 & ...... \\
\hline $7-\ldots$ & B & 0.9 & 0.6 & 77. 3 & 17.6 & 3.6 & ...... & 100.0 & 1,081 & .669 \\
\hline $8 \ldots \ldots$ & B & 1.0 & .4 & 76.8 & 18. 1 & 3.7 & ...... & 100.0 & 1,084 & .671 \\
\hline 9 & A & 1.1 & .8 & 75.0 & 18. 7 & 4.4 & ...... & 100.0 & 1,077 & .680 \\
\hline 10 & A & 1.0 & .3 & 76.2 & 18. 6 & 3.9 & ...... & 100.0 & 1,087 & .674 \\
\hline $11 \ldots$ & $\mathrm{C}$ & 0.9 & .2 & 77.1 & 18.3 & 3.5 & ...... & 100.0 & 1,091 & .669 \\
\hline 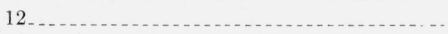 & $\mathrm{B}$ & 1.0 & .2 & 75.7 & 18.8 & 4.3 & -..... & 100.0 & 1,086 & .676 \\
\hline 13 & $\mathrm{~B}$ & ....... & ...... & 76.8 & 19.1 & -..... & ...... & ...... & 1,102 & ...... \\
\hline 14 & $\mathrm{~B}$ & -...... & ..... & 77.8 & 18.3 & -.... & ..... & ..... & 1,098 & ..... \\
\hline$A v g \ldots \ldots \ldots$ & ...... & 1.0 & 0.3 & 76.6 & 18.3 & 3.8 & ....... & ...... & 1,086 & 0.672 \\
\hline
\end{tabular}

LABORATORY NUMBER 6

\begin{tabular}{|c|c|c|c|c|c|c|c|c|c|c|}
\hline $1 \ldots$ & - & 0.9 & 0.0 & 76.8 & 19.5 & 2.8 & $\ldots \ldots$ & 100.0 & 1,104 & 0.671 \\
\hline $2 \ldots$ & . & .9 & .2 & 77.8 & 18. 7 & 2.4 & ........ & 100.0 & 1,105 & .667 \\
\hline $3 \ldots$ & $\ldots$ & .9 & .1 & 77.9 & 18.3 & 2.8 & & 100.0 & 1,099 & .666 \\
\hline $4 \ldots$ & & .9 & 2 & 78.5 & 18.1 & 2.3 & ... & 100.0 & 1,101 & .663 \\
\hline $5 \ldots$ & $\ldots$ & 1.0 & 0 & 77.0 & 19.8 & 2. 2 & $\ldots$ & 100.0 & 1,116 & 671 \\
\hline $6 \ldots$ & $\ldots$ & 1.0 & .0 & 78.7 & 17.3 & 3.0 & . . . . & 100.0 & 1,089 & .662 \\
\hline $7 \ldots$ & & 0.9 & .0 & 78.7 & 18.7 & 1.7 & - & 100.0 & 1,114 & .663 \\
\hline $8 \ldots$ & $\ldots$ & 1.0 & .1 & 76.1 & 19.6 & 3.2 & - . . & 100.0 & 1,104 & .675 \\
\hline $9 \ldots$ & & 1.0 & .1 & 74.3 & 20.6 & 4.0 & ......... & 100.0 & 1,104 & .683 \\
\hline $10 \ldots \ldots$ & & 0.9 & .1 & 75.1 & 20.5 & 3.4 & ........ & 100.0 & 1,109 & .679 \\
\hline Avg & & 0.9 & 0.1 & 77.1 & 19.1 & 2.8 & ....... & 100.0 & 1,105 & 0.670 \\
\hline
\end{tabular}


TABLE 1.-Analytical data reported by the cooperatiing laboratories-Continued

LABORATORY NUMBER 7

A pparatus $\mathrm{V}_{1} \mathrm{R}_{1} \mathrm{Hg}$-Allen

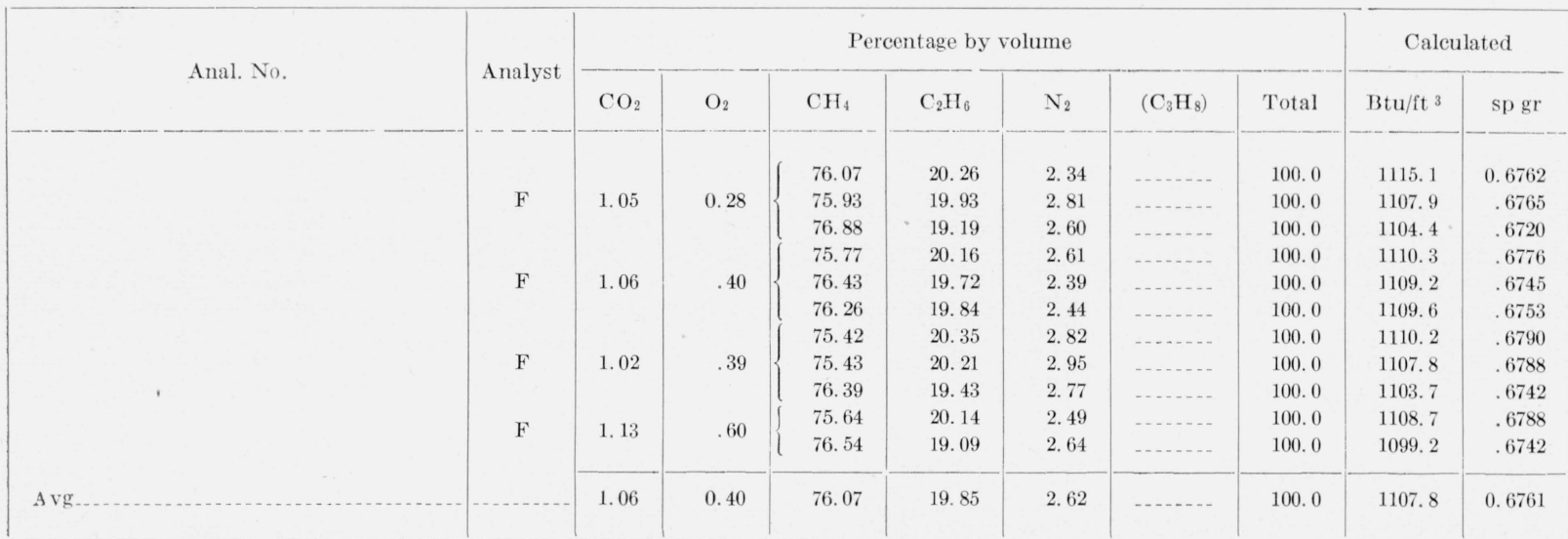

LABORATORY NUMBER 8

Apparatus $\mathrm{V}_{1} \mathrm{R}_{1} \mathrm{Hg}$-Burrell

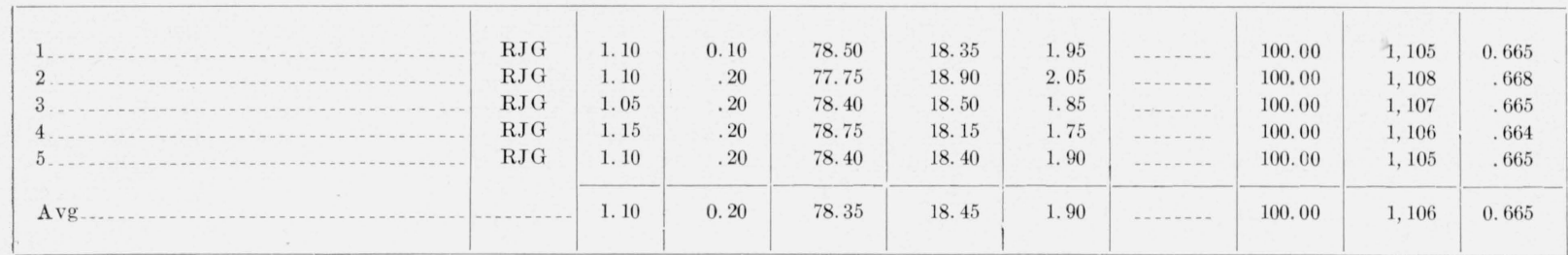

Method $A$

LABORATORY NUMBER 9

\begin{tabular}{|c|c|c|c|c|c|c|c|c|c|c|}
\hline $1 \ldots$ & MLN & 0.8 & 0.1 & 76.2 & 19.1 & 3.8 & $\ldots$ & 100.0 & 1,096 & 0.673 \\
\hline $2 \ldots$ & $\mathrm{MLN}$ & .9 & .2 & 75.3 & 20.1 & 3.5 & $\ldots$ & 100.0 & 1,105 & .678 \\
\hline $3 \ldots$ & MLN & .7 & .2 & 75.5 & 20.1 & 3.5 & ...... & 100.0 & 1,107 & .676 \\
\hline $4 \ldots \ldots$ & MLN & .7 & .1 & 74.9 & 20.6 & 3.7 & ...... & 100.0 & 1,109 & .679 \\
\hline $5 \ldots$ & MLN & .9 & .2 & 76.8 & 19.2 & 2.9 & ...... & 100.0 & 1,104 & .679 \\
\hline $6 \ldots \ldots$ & MLN & .9 & .2 & 76.3 & 19.5 & 3.1 & .... & 100.0 & 1,104 & .674 \\
\hline $7 \ldots \ldots$ & MLN & 1.0 & .2 & 75.6 & 20.1 & 3.1 & ...... & 100.0 & 1,108 & .678 \\
\hline 8. & MLN & 0.7 & .1 & 77. 7 & 19.0 & 2.5 & ....... & 100.0 & 1,109 & .666 \\
\hline 9 & MLN & .6 & .2 & 76.6 & 19.5 & 3.1 & ....... & 100.0 & 1,107 & .671 \\
\hline 10 & MLN & 9 & 1 & 77.3 & 18.9 & 2.8 & -..... & 100.0 & 1,104 & 663 \\
\hline$A v g \ldots$ & ....... & 0.81 & 0.16 & 76.22 & 19.61 & 3.10 & ....... & & 1,105 & 0.674 \\
\hline
\end{tabular}

Method $A$

LABORATORY NUMBER 10

\begin{tabular}{|c|c|c|c|c|c|c|c|c|c|c|}
\hline $1 \ldots \ldots$ & ....... & 1.17 & 0.53 & 74.34 & 18. 10 & 5.86 & (....... & 100.00 & 1,060 & 0.683 \\
\hline $2 \ldots \ldots \ldots$ & ....... & 1.18 & .54 & 75.53 & 18.10 & 4.65 & -..... & 100.00 & 1,072 & .678 \\
\hline 3 & ...... & 1.18 & .43 & 75.49 & 19.46 & 3.44 & ...... & 100.00 & 1,095 & .679 \\
\hline $4 \ldots$ & ...... & 1.12 & .41 & 77. 16 & 18.28 & 3.03 & $\ldots$ & 100.00 & 1,091 & .671 \\
\hline n.............. & ....... & 1.28 & .43 & 79.42 & 17.07 & 1.80 & ....... & 100.00 & 1,092 & .661 \\
\hline $6 \ldots$. & -..... & 1.12 & .41 & 78.16 & 16.83 & 3.48 & ...... & 100.00 & 1,076 & .665 \\
\hline 7 & -..... & 1.25 & .42 & 78.70 & 17.05 & 2.58 & & 100.00 & 1,085 & .669 \\
\hline 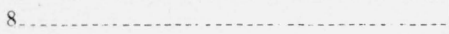 & -..... & 1. 14 & .41 & 77. 13 & 17.83 & 3.49 & ....... & 100.00 & 1,083 & .671 \\
\hline 9 & ....... & 1.17 & .43 & 79.57 & 16. 96 & 1.87 & ...... & 100.00 & 1,092 & .660 \\
\hline 10 & -..... & 1.06 & .42 & 78.88 & 17.40 & 2.24 & ........ & 100.00 & 1,093 & .662 \\
\hline Avg_- & ...... & 1.17 & 0.44 & 77.44 & 17. 71 & 3.24 & ....... & 100.00 & 1,084 & 0.670 \\
\hline
\end{tabular}


TABLE 1.-Analytical data reported by the cooperating laboratories-Continued

LABORATORY NUMBER 11

Method $A$

Apparatus $\mathrm{V}_{1} \mathrm{R}_{1} \mathrm{Hg}$.

\begin{tabular}{|c|c|c|c|c|c|c|c|c|c|c|}
\hline \multirow{2}{*}{ Anal. No. } & \multirow{2}{*}{ Analyst } & \multicolumn{7}{|c|}{ Percentage by volume } & \multicolumn{2}{|c|}{ Calculated } \\
\hline & & $\mathrm{CO}_{2}$ & $\mathrm{O}_{2}$ & $\mathrm{CH}_{4}$ & $\mathrm{C}_{2} \mathrm{H}_{6}$ & $\mathrm{~N}_{2}$ & $\left(\mathrm{C}_{3} \mathrm{H}_{8}\right)$ & Total & $\mathrm{Btu} / \mathrm{ft}^{3}$ & sp. gr \\
\hline $1 \ldots$ & $\mathrm{HFB}$ & 1.00 & 0.30 & 16.70 & 80.00 & 2.00 & ......-. & 100.00 & 1,092 & 0.657 \\
\hline $2 \ldots$ & HFB & 1.00 & .30 & 17.20 & 78.80 & 2. 70 & -..... & 100.00 & 1,088 & .662 \\
\hline $3 \ldots$ & HFB & 1.00 . & .40 & 17.00 & 79.30 & 2. 30 & -...... & 100.00 & 1,090 & .660 \\
\hline $4 \ldots$ & HFB & 1.05 & .35 & 17. 50 & 78.30 & 2.80 & -...... & 100.00 & 1,089 & .665 \\
\hline $5 \ldots$ & HFB & 1.05 & .40 & 16.80 & 79.90 & 1.85 & -..... & 100.00 & 1,092 & .657 \\
\hline $6 \ldots$ & HFB & 1.05 & .35 & 17. 00 & 79.95 & 1.65 & -....... & 100.00 & 1,096 & .657 \\
\hline $7 \ldots$ & HFB & 1.00 & .40 & 16.80 & 80.10 & 1. 70 & -...... & 100.00 & 1,095 & .656 \\
\hline $8 \ldots$ & HFB & 1.00 & .30 & 17. 10 & 79.80 & 1.80 & .....- & 100.00 & 1,096 & .657 \\
\hline $9 \ldots$ & HFB & 1.00 & .40 & 17.40 & 78. 70 & 2. 50 & -...... & 100.00 & 1,092 & .663 \\
\hline $10 \ldots$ & $\mathrm{HFB}$ & 1.05 & .35 & 16.90 & 79.90 & 1.80 & -...... & 100.00 & 1,094 & .657 \\
\hline Avg... & - & 1.02 & 0.35 & 17.04 & 79.48 & 2.11 & -..... & 100.00 & $1,092.4$ & 0.659 \\
\hline
\end{tabular}

Method $A$

LABORATORY NUMBER 12

\begin{tabular}{|c|c|c|c|c|c|c|c|c|c|c|}
\hline $1 \ldots$ & $\mathrm{R}$ & 0.9 & 0.1 & 85.2 & 13.7 & 0.1 & ....... & 100.0 & 1,091 & 0.632 \\
\hline 2. & $\mathrm{R}$ & 1.0 & .1 & 82.2 & 16.4 & .3 & - & 100.0 & 1,108 & .647 \\
\hline $3 \ldots$ & $\mathrm{R}$ & 0.9 & .1 & 79.7 & 17. 7 & 1.6 & ...... & 100.0 & 1,106 & .658 \\
\hline 4 & $\mathrm{R}$ & .9 & .1 & 82.8 & 15.5 & 0.7 & - & 100.0 & 1,098 & .643 \\
\hline $5 \ldots$ & $\mathrm{R}$ & .9 & .1 & 83.9 & 14.7 & .4 & -..... & 100.0 & 1,095 & .639 \\
\hline A vg & 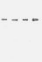 & 0.9 & 0.1 & 82.8 & 15.6 & $\begin{array}{c}0.6 \\
\text { (by diff.) }\end{array}$ & ....... & 100.0 & 1,100 & 0.643 \\
\hline
\end{tabular}

$\cdot$ Method $A$

LABORATORY NUMBER 13

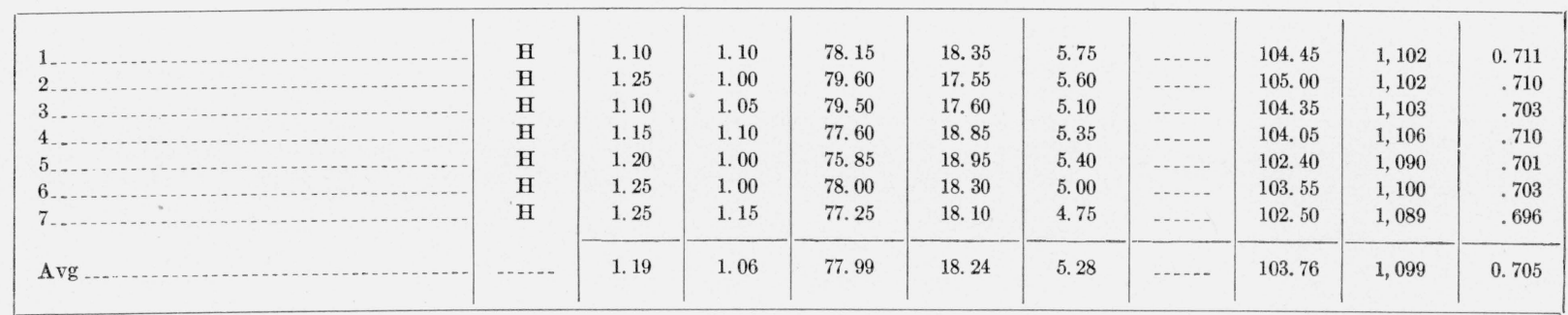

LABORATORY NUMBER 14

Method $A$

Apparatus $\mathrm{V}_{1} \mathrm{R}_{1} \mathrm{Hg}$-Elliott-Burrell

\begin{tabular}{|c|c|c|c|c|c|c|c|c|c|c|}
\hline $1 \ldots \ldots$ & A & 0.8 & 0.4 & 79.0 & 17.4 & 2.4 & -..... & 100.0 & 1,094 & 0.661 \\
\hline $2 \ldots+20$ & A & .9 & .4 & 78.8 & 17.2 & 2. 7 & -..... & 100.0 & 1,089 & .662 \\
\hline 3 & A & .8 & .3 & 78.4 & 17. 3 & 3.2 & ..... & 100.0 & 1,086 & .663 \\
\hline $4 \ldots$ & A & 1. 0 & .2 & 78.0 & 17. 9 & 2.9 & -..... & 100.0 & 1,093 & .666 \\
\hline 5 & A & 0.8 & .3 & 78.4 & 17.3 & 3. 2 & ...... & 100.0 & 1,086 & .663 \\
\hline 6 & $\mathrm{~B}$ & 1.1 & .3 & 79.3 & 17.4 & 1.9 & -.... & 100.0 & 1,097 & .661 \\
\hline $7 \ldots$ & B & 1.0 & .4 & 77.9 & 18.0 & 2.7 & -.... & 100.0 & 1,094 & .667 \\
\hline $8 \ldots$ & B & 1.0 & .4 & 77.2 & 18.4 & 3.0 & ...... & 100.0 & 1,094 & .670 \\
\hline 9 & $\mathrm{~B}$ & 1.1 & .3 & 76.7 & 18.9 & 3. 0 & -..... & 100.0 & 1,097 & .673 \\
\hline 10 & B & 1.0 & .3 & 79.4 & 17.6 & 1. 7 & (n.... & 100.0 & 1,102 & .660 \\
\hline Avg & $\cdots$ & 1.0 & 0.3 & 78.3 & 17.7 & 2.7 & -..... & 100.0 & 1,093 & 0.665 \\
\hline
\end{tabular}


TABLE 1.-Analytical data reported by the cooperating laboratories-Continued

LABORATORY NUMBER 15

Apparatus $\mathrm{V}_{3} \mathrm{R}_{1} \mathrm{R}_{2} \mathrm{H}_{2} \mathrm{O}-\mathrm{Na}_{2} \mathrm{SO}_{4} \mathrm{H}_{2} \mathrm{SO}_{4}$ Modified Williams

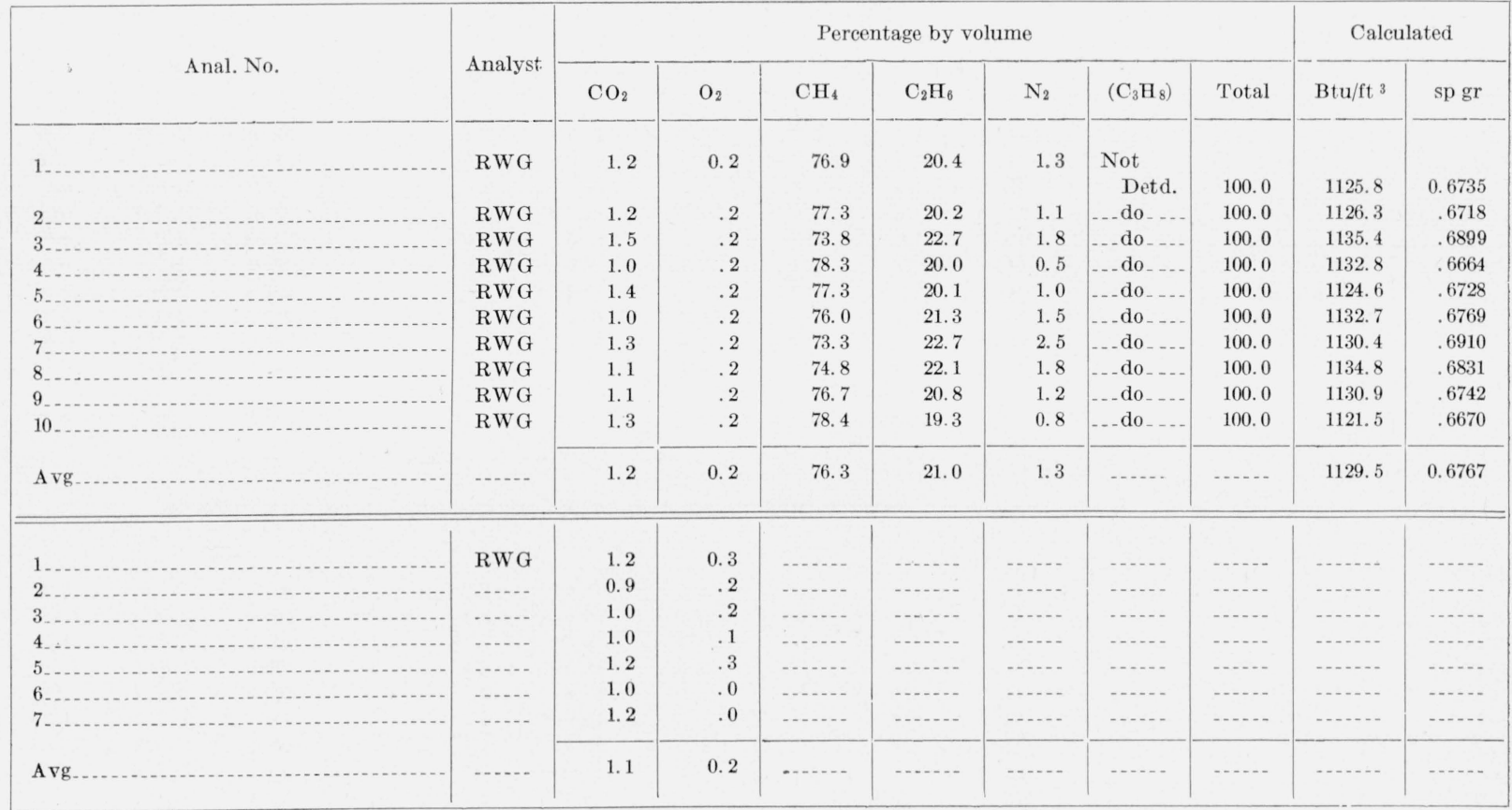

Method $A$

LABORATORY NUMBER 16

\begin{tabular}{|c|c|c|c|c|c|c|c|c|c|c|}
\hline $1 \ldots$ & $\mathrm{U}$ & 1. 0 & 0.0 & 74.5 & 20.5 & 4. 0 & . & 100.0 & 1,104 & 0.682 \\
\hline $2 \ldots$ & $\mathrm{U}$ & 1. 0 & .0 & 75.1 & 19.9 & 4.0 & ..... & 100.0 & 1,099 & .679 \\
\hline $3 \ldots$ & $\mathrm{U}$ & 0.9 & .0 & 76.7 & 18.9 & 3.5 & . & 100.0 & 1,097 & .671 \\
\hline $4 \ldots$ & $\mathrm{U}$ & 1.0 & .0 & 76.4 & 19.9 & 2.7 & -.... & 100.0 & 1,112 & .674 \\
\hline $5^{\mathrm{b}} \ldots \ldots \ldots$ & $\mathrm{U}$ & .9 & .0 & 76.6 & 18.9 & 3.6 & . & 100.0 & 1,096 & .671 \\
\hline Avg. & $\ldots$ & 1.0 & 0.0 & 75.9 & 19.6 & 3.5 & , & 100.0 & 1,102 & 0.675 \\
\hline
\end{tabular}

Method $A$

LABORATORY MUMBER 17

\begin{tabular}{|c|c|c|c|c|c|c|c|c|c|c|}
\hline 1 & A & 1. 0 & 0.1 & 76.9 & 19. 2 & 2.8 & $\ldots$ & 100.0 & 1,105 & 0.671 \\
\hline $2 \ldots$ & A & 1. 0 & .1 & 76.5 & 19. 2 & 3.2 & ...... & 100.0 & 1,101 & .673 \\
\hline 3 & A & 1. 0 & .1 & 77.5 & 18. 7 & 2. 7 & ....... & 100.0 & 1,102 & .669 \\
\hline $4 \ldots$ & A & 0.9 & .1 & 77.6 & 18. 7 & 2. 7 & ...... & 100.0 & 1,103 & .668 \\
\hline $5 \ldots$ & A & 1.0 & .1 & 77.5 & 18.7 & 2. 7 & :..... & 100.0 & 1,102 & .669 \\
\hline $6 \ldots$ & A & 1.0 & .0 & 76.8 & 19.5 & 2. 7 & ....... & 100.0 & 1,109 & .672 \\
\hline $7 \ldots$ & A & 1. 0 & .0 & 77.6 & 18.9 & 2.5 & ........ & 100.0 & 1,106 & .668 \\
\hline 8 & A & 0.9 & .1 & 76.8 & 19. 5 & 2. 7 & ....... & 100.0 & 1,109 & .672 \\
\hline 9 & $\mathrm{~A}$ & 1.0 & .1 & 76.9 & 19.2 & 2.8 & ....... & 100.0 & 1,105 & .671 \\
\hline 10 … & A & 1. 0 & .0 & 76.8 & 19.5 & 2.7 & (n...... & 100.0 & 1,109 & .672 \\
\hline Avg $\ldots$ & $-\ldots$ & 0.98 & 0.07 & 77.09 & 19.11 & 2.75 & -..... & -..... & 1,105 & 0.671 \\
\hline $1 \ldots$. & $\mathrm{B}$ i & 1.0 & 0.0 & 77.2 & 18.9 & 2. 9 & , n.... & 100.0 & 1,102 & 0.670 \\
\hline $2 \ldots$ & $\mathrm{B}$ & 1.0 & .0 & 77.2 & 18.7 & 3.1 & -..... & 100.0 & 1,099 & .670 \\
\hline Avg... & ...... & 1.0 & 0.0 & 77.2 & 18.8 & 3.0 & ...... & ...... & 1,101 & 0.670 \\
\hline
\end{tabular}

See footnotes at end of table. 
TABLE 1.-Analytical data reported by the cooperating laboratories-Continued

Apparatus $\mathrm{V}_{1} \mathrm{H}_{1} \mathrm{Hg}$-Bureau of Mines

\begin{tabular}{|c|c|c|c|c|c|c|c|c|c|c|}
\hline \multirow{2}{*}{ Anal. No. } & \multirow{2}{*}{ Analyst } & \multicolumn{7}{|c|}{ Percentage by volume } & \multicolumn{2}{|c|}{ Calculated } \\
\hline & & $\mathrm{CO}_{2}$ & $\mathrm{O}_{2}$ & $\mathrm{CH}_{4}$ & $\mathrm{C}_{2} \mathrm{H}_{6}$ & $\mathrm{~N}_{2}$ & $\left(\mathrm{C}_{3} \mathrm{H}_{8}\right)$ & Total & $\mathrm{Btu} / \mathrm{ft}^{3}$ & sp gr \\
\hline $1 \ldots$ & $\mathrm{H}$ & 1.0 & 0.2 & 77.5 & 18. 9 & 2.4 & .... & 100.0 & 1105.5 & 0.6688 \\
\hline 2 & $\mathrm{H}$ & 1.3 & .0 & 76.9 & 19.2 & 2.6 & & 100.0 & 1101.7 & .6730 \\
\hline $3 \ldots$ & $\mathrm{H}$ & 1.0 & .0 & 77.1 & 19.2 & 2.7 & ....... & 100.0 & 1106.7 & .6705 \\
\hline $4 \ldots$ & $\mathrm{H}$ & 1.0 & .2 & 77.7 & 18.7 & 2.7 & ....... & 100.0 & 1103.9 & .6678 \\
\hline 5 & $\mathrm{H}$ & 1.0 & .0 & 77.3 & 19.3 & 2.4 & & 100.0 & 1110.5 & .6697 \\
\hline $6 \ldots$ & $\mathrm{M}$ & 0.7 & .2 & 77.7 & 18.9 & 2.5 & .... & 100.0 & 1107.5 & .6663 \\
\hline 7 & M & 1.3 & .0 & 77.3 & 19.0 & 2.4 & . & 100.0 & 1105.2 & .6711 \\
\hline $8 \ldots$ & $\mathrm{M}$ & 1.1 & .0 & 76.8 & 19.2 & 2.9 & & 100.0 & 1103.7 & .6723 \\
\hline 9 & M & 1.0 & .3 & 77.3 & 19.0 & 2.4 & ...... & 100.0 & 1105.2 & .6699 \\
\hline $10 \ldots$ & M & 1.0 & .3 & 78.1 & 18.7 & 1. 9 & ...... & 100.0 & 1107.9 & .6663 \\
\hline $\mathrm{A} \vee \mathrm{g}$. & ..... & 1. 04 & 0.12 & 77.37 & 19. 01 & 2.46 & ...... & 100.0 & 1106.1 & 0.6696 \\
\hline
\end{tabular}

\begin{tabular}{|c|c|c|c|c|c|c|c|c|c|c|}
\hline \multirow[t]{2}{*}{1} & \multicolumn{10}{|c|}{ Same experimental data as above, but corrected for $0.14 \mathrm{ml}$ of water in burette } \\
\hline & $\mathrm{H}$ & 1.0 & 0.2 & 76.3 & 19.6 & 2.9 & ...... & 100.0 & 1105.8 & 0.6744 \\
\hline $2 \ldots$ & $\mathrm{H}$ & 1.3 & .0 & 75.7 & 19.9 & 3.1 & - & 100.0 & 1105.0 & .6785 \\
\hline $3 \ldots$ & $\mathrm{H}$ & 1.0 & .0 & 75.9 & 20.0 & 3.1 & - & 100.0 & 1108.8 & .6761 \\
\hline $4 \ldots \ldots$ & $\mathrm{H}$ & 1.0 & .2 & 76.6 & 19.4 & 2. 8 & -....... & 100.0 & 1105.2 & .6730 \\
\hline $5 \ldots$ & $\mathrm{H}$ & 1.0 & .0 & 76.0 & 20.0 & 30 & $\ldots$ & 100.0 & 1109.8 & .6757 \\
\hline $6 \ldots$ & M & 0.7 & .2 & 76.5 & 19.6 & 3. 0 & ....... & 100.0 & 1107.8 & .6719 \\
\hline $7 \ldots$ & M & 1.3 & .0 & 76.1 & 19.8 & 2.8 & ....... & 100.0 & 1107.3 & .6768 \\
\hline $8 \ldots$ & M & 1.1 & .0 & 75.6 & 20.0 & 3.3 & ....- & 100.0 & 1105.8 & .6779 \\
\hline $9 \ldots$ & M & 1.0 & .3 & 76.2 & 19.8 & 2.7 & -....... & 100.0 & 1108.3 & .6751 \\
\hline 10. & M & 1.0 & .3 & 76.9 & 19.4 & 2.4 & ....... & 100.0 & 1109.2 & .6718 \\
\hline A vg & ....... & 1.04 & 0.12 & 76.18 & 19.75 & 2. 91 & ........ & 100.0 & 1107.2 & 0.6751 \\
\hline
\end{tabular}

Method $A$

LABORATORY NUMBER 19

\begin{tabular}{|r|c|c|c|c|c|c|c|c|}
\hline & & & & & & \\
1
\end{tabular}


TABLE 1.-Analytical data reported by the cooperating laboratories-Continued

Method $A$

LABORATORY NUMBER 20

Apparatus $\mathrm{V}_{1} \mathrm{R}_{1} \mathrm{Hg}-\mathrm{U}$. S. Steel

\begin{tabular}{|c|c|c|c|c|c|c|c|c|c|c|}
\hline \multirow{2}{*}{ Anal. No. } & \multirow{2}{*}{ Analyst } & \multicolumn{7}{|c|}{ Percentage by volume } & \multicolumn{2}{|c|}{ Calculated } \\
\hline & & $\mathrm{CO}_{2}$ & $\mathrm{O}_{2}$ & $\mathrm{CH}_{4}$ & $\mathrm{C}_{2} \mathrm{H}_{6}$ & $\mathrm{~N}_{2}$ & $\left(\mathrm{C}_{3} \mathrm{H}_{8}\right)$ & Total & $\mathrm{Btu} / \mathrm{ft}^{3}$ & $\operatorname{spgr}$ \\
\hline 1. & A & 0.9 & 0.1 & 78.9 & 17.6 & 2.5 & Not detd & 100.0 & 1,097 & 0.6613 \\
\hline 2. & A & .9 & .1 & 78.7 & 18.2 & 2.1 & . do & 100.0 & 1,105 & .6626 \\
\hline 3 & A & 1.0 & .1 & 81.1 & 15.7 & 2. 1 & $\ldots \mathrm{do} \ldots$ & 100.0 & 1,086 & .6512 \\
\hline $4 \ldots \ldots$ & A & 1.0 & .1 & 79.1 & 17.5 & 2. 3 & ... do & 100.0 & 1,097 & .6609 \\
\hline $5 \ldots$ & A & 0.9 & .1 & 78.7 & 17.8 & 2.5 & $\ldots$ do & 100.0 & 1,098 & .6623 \\
\hline 6. & A & .9 & .1 & 79.3 & 17. 3 & 2.4 & ...do_... & 100.0 & 1,095 & .6594 \\
\hline $7 \ldots$ & A & 1.0 & .2 & 78.5 & 18.0 & 2.3 & ... do & 100.0 & 1,100 & .6639 \\
\hline $8 \ldots$ & A & 1. 0 & .2 & 77.1 & 18. 9 & 2.8 & $\ldots$. do_... & 100.0 & 1,101 & .6705 \\
\hline $9 \ldots \ldots$ & A & 1.0 & .2 & 78.1 & 18.2 & 2.5 & $\ldots$ do...... & 100.0 & 1,099 & .6658 \\
\hline Avg & -..... & 1.0 & 0.1 & 78.8 & 17. 7 & 2.4 & -..... & 100.0 & 1,098 & 0.6620 \\
\hline 1. & B & 0.9 & 0.0 & 78.9 & 17. 5 & 2. 7 & Not detd. & 100.0 & 1,095 & 0.6615 \\
\hline 2 & B & .9 & .0 & 80.2 & 16.5 & 2.4 & ... do & 100.0 & 1,090 & .6549 \\
\hline 3 & B & .9 & .0 & 76.9 & 19.5 & 2. 7 & $\ldots$ do & 100.0 & 1,109 & .6714 \\
\hline $4 \ldots \ldots$ & $\mathrm{B}$ & .9 & .0 & 79.3 & 17.5 & 2. 3 & ... do .... & 100.0 & 1,099 & .6594 \\
\hline $5 \ldots$ & $\mathrm{B}$ & .9 & .1 & 77.4 & 19.2 & 2.4 & ... do..... & 100.0 & 1,110 & .6688 \\
\hline 6 & B & .9 & .1 & 79.2 & 17.8 & 2.0 & $\ldots$ do $\ldots . . .$. & 100.0 & 1,103 & .6602 \\
\hline $7 \ldots$ & B & .9 & .0 & 78.7 & 17. 7 & 2.7 & .... do .... & 100.0 & 1,096 & .6624 \\
\hline $8 \ldots$ & $\mathrm{B}$ & .9 & .0 & 79.0 & 17.8 & 2. 3 & ... do_... & 100.0 & 1,101 & .6609 \\
\hline $9 \ldots$ & B & .9 & .1 & 78.0 & 18. 9 & 2.1 & ... do ..... & 100.0 & 1,111 & .6660 \\
\hline Avg... & - & 0.9 & 0.0 & 78.7 & 18. 0 & 2.4 & ....... & 100.0 & 1,102 & 0.6628 \\
\hline
\end{tabular}

Method $I I$

LABORATORY NUMBER 21

Apparatus $\mathrm{V}_{2} \mathrm{R}_{1} \mathrm{Hg}$-Burrell

\begin{tabular}{|c|c|c|c|c|c|c|c|c|c|c|c|}
\hline \multirow{2}{*}{ Anal. No. } & \multirow{2}{*}{ Analyst } & \multicolumn{8}{|c|}{ Percentage by volume } & \multicolumn{2}{|c|}{ Calculated } \\
\hline & & $\mathrm{CO}_{2}$ & $\mathrm{O}_{2}$ & $\mathrm{CH}_{4}$ & $\mathrm{C}_{2} \mathrm{H}_{6}$ & $\mathrm{~N}_{2}$ & $\mathrm{C}_{2} \mathrm{H}_{4}$ & $\mathrm{CO}$ & $\mathrm{H}_{2}$ & $\mathrm{Btu} / \mathrm{ft}^{3}$ & $\mathrm{sp} g r$ \\
\hline 1. & 1 & 1.0 & 0.0 & 75.5 & 17.3 & 4.4 & 0.6 & 0.4 & 0.8 & 1070.6 & 0.6684 \\
\hline . & 1 & 1.0 & 0 & 73.4 & 18.1 & 6.0 & .5 & .5 & .5 & 1061.5 & .6805 \\
\hline 3. & 1 & 1.0 & .0 & 74.3 & 17.7 & 5.2 & .8 & .5 & .5 & 1068.2 & .6765 \\
\hline $4 \ldots$ & 1 & 1.0 & .0 & 74.6 & 17.2 & 5.7 & .5 & .5 & .5 & 1057.7 & .6748 \\
\hline 5. & 1 & 1. 0 & .0 & 74.7 & 17.7 & 5.0 & .8 & .5 & .3 & 1071.5 & .6766 \\
\hline A vg - - & -.... - & 1.0 & .0 & 74.5 & 17.6 & 5.3 & .6 & .5 & .5 & 1065.9 & .6754 \\
\hline
\end{tabular}


TABLE 1.-Analytical data reported by the cooperating laboratories-Continued

\begin{tabular}{|c|c|c|c|c|c|c|c|c|c|c|}
\hline \multirow{2}{*}{ Anal. No. } & \multirow{2}{*}{ Analyst } & \multicolumn{7}{|c|}{ Percentage by volume } & \multicolumn{2}{|c|}{ Calculated } \\
\hline & & $\mathrm{CO}_{2}$ & $\mathrm{O}_{2}$ & $\mathrm{CH}_{4}$ & $\mathrm{C}_{2} \mathrm{H}_{6}$ & $\mathrm{~N}_{2}$ & $\left(\mathrm{C}_{3} \mathrm{H}_{8}\right)$ & Total & $\mathrm{Btu} / \mathrm{ft}^{3}$ & sp gr \\
\hline $1 \ldots$ & M & 1.0 & 0.0 & 72.8 & 21.7 & 4.5 & -..... & 100.0 & 1,108 & 0.690 \\
\hline $2 \ldots$ & M & 1.1 & .1 & 75.1 & 19.9 & 3.8 & - & 100.0 & 1,099 & .680 \\
\hline $3 \ldots$ & M & 1.9 & .0 & 73.6 & 21.3 & 4.1 & ...... & 100.0 & 1,109 & .687 \\
\hline $4 \ldots$ & M & 1.0 & .0 & 73.4 & 22.1 & 3.5 & -.... & 100.0 & 1,121 & .688 \\
\hline $5 \ldots$ & M & 1.0 & .1 & 73.3 & 21.0 & 4. 6 & -..... & 100.0 & 1,101 & .688 \\
\hline $6 \ldots \ldots$ & M & 1.0 & .1 & 76.6 & 19.1 & 3. 2 & ...... & 100.0 & 1,100 & .673 \\
\hline $7 \ldots$ & M & 1.0 & .0 & 72.7 & 21.4 & 4. 9 & - . & 100.0 & 1,102 & .691 \\
\hline $8 \ldots \ldots$ & M & 1.0 & .0 & 72.7 & 22.0 & 4. 3 & - . . & 100.0 & 1,112 & .691 \\
\hline $9 \ldots$ & M & 1.0 & .0 & 74.0 & 21.3 & 3. 7 & ...... & 100.0 & 1,113 & .685 \\
\hline $10 \ldots \ldots$ & M & 1.0 & 0 & 74.4 & 21.1 & 3.5 & - n. - & 100.0 & 1,113 & .684 \\
\hline Avg ... & -..... & 1.0 & 0.0 & 73.9 & 21.1 & 4.0 & - n.... & 100.0 & 1,108 & .686 \\
\hline $1 \ldots$ & $\mathrm{N}$ & 0.9 & 0.1 & 74.4 & 20.7 & 4.1 & . . & 100.2 & 1,106 & 0.684 \\
\hline $2 \ldots \ldots$ & $\mathrm{N}$ & .9 & .0 & 74.8 & 20.4 & 4.0 & - & 100.1 & 1,105 & .681 \\
\hline $3 \ldots \ldots$ & $\mathrm{N}$ & 1.0 & .0 & 75.9 & 19.8 & 3.9 & ...... & 100.6 & 1,105 & .676 \\
\hline Avg $\ldots$ & - & 0.9 & 0.0 & 75.0 & 20.3 & 4.0 & - & 100.3 & 1,105 & .680 \\
\hline
\end{tabular}

LABORATORY NUMBER 23

\begin{tabular}{|c|c|c|c|c|c|c|c|c|c|c|}
\hline $1 \ldots$ & M & 1.0 & 0.2 & 76.6 & 18.8 & 3.4 & $\ldots . .$. & 100.0 & 1,095 & 0.672 \\
\hline $2 \ldots \ldots$ & M & 1.0 & .2 & 75.5 & 19.7 & 3.6 & ...... & 100.0 & 1,100 & .678 \\
\hline $3 \ldots \ldots$ & M & 1.0 & .1 & 77.8 & 18.4 & 2.6 & - n & 100.0 & 1,100 & .666 \\
\hline $4 \ldots \ldots$ & M & 1.0 & .2 & 77.8 & 18.5 & 2.5 & ....... & 100.0 & 1,101 & .667 \\
\hline $5 \ldots \ldots \ldots$ & M & 1.0 & .2 & 77.3 & 18.5 & 3.0 & ...... & 100.0 & 1,096 & .669 \\
\hline 6 & M & 1.0 & .2 & 77.0 & 18.7 & 3.1 & - n... & 100.0 & 1,097 & .671 \\
\hline 7 & $\mathrm{M}$ & 1. 0 & .2 & 74.5 & 20.2 & 4.1 & -.... & 100.0 & 1,098 & .682 \\
\hline $8 \ldots \ldots$ & M & 1.0 & .2 & 78.4 & 18.3 & 2.1 & ....... & 100.0 & 1,104 & .665 \\
\hline 9 & M & 1.0 & .2 & 78.6 & 17.9 & 2.3 & -..... & 100.0 & 1,099 & .663 \\
\hline 10 & M & 1. 0 & .2 & 76.4 & 19.0 & 3.4 & ...... & 100.0 & 1,096 & .673 \\
\hline $11 \ldots \ldots$ & M & 1.0 & .2 & 76.1 & 18.3 & 4.4 & - & 100.0 & 1,081 & .674 \\
\hline 12 & M & 1.0 & .2 & 75.8 & 18.6 & 4.4 & -..... & 100.0 & 1,083 & .676 \\
\hline 13 & M & 1.0 & .2 & 77.0 & 19.3 & 2.5 & -..... & 100.0 & 1,107 & .671 \\
\hline 14 & M & 1.0 & .2 & 76.4 & 19.5 & 2.9 & - . & 100.0 & 1,105 & .674 \\
\hline 15 & M & 1.0 & .2 & 76.9 & 19.1 & 2.8 & -..... & 100.0 & 1,102 & .671 \\
\hline $16 \ldots \ldots$ & M & 1.0 & .2 & 77.9 & 19.0 & 1.9 & -..... & 100.0 & 1,111 & .668 \\
\hline Avg... & $-\ldots$ & 1.0 & 0.2 & 76.9 & 18.9 & 3.1 & -..... & 100.0 & 1,099 & 0.671 \\
\hline $1 \ldots$ & $\mathrm{K}$ & 1.0 & 0.2 & 75.1 & 20.2 & 3.5 & -..... & 100.0 & 1,104 & 0.679 \\
\hline 2 & $\mathrm{~K}$ & 1.0 & .2 & 74.7 & 20.4 & 3.7 & -.... & 100.0 & 1,104 & .682 \\
\hline 3 & $\mathrm{~K}$ & 1. 0 & .2 & 74.8 & 20.3 & 3.7 & -..... & 100.0 & 1,103 & .680 \\
\hline 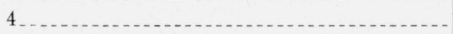 & $\mathrm{K}$ & 1. 0 & .2 & 75.7 & 19. 7 & 3.4 & ...... & 100.0 & 1,102 & .675 \\
\hline 5 & $\mathrm{~K}$ & 1.0 & .2 & 75.2 & 19. 7 & 3.9 & -..... & 100.0 & 1,097 & .679 \\
\hline 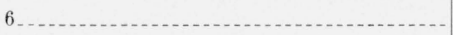 & $\mathrm{K}$ & 1.0 & .2 & 74.7 & 20.3 & 3.8 & -.... & 100.0 & 1,102 & .681 \\
\hline 7 & $\mathrm{~K}$ & 1.0 & .2 & 74.9 & 20.5 & 3.4 & - n... & 100.0 & 1,108 & .680 \\
\hline 8 - & $\mathrm{K}$ & 1.0 & .2 & 75.7 & 19.7 & 3.4 & ...... & 100.0 & 1,102 & .676 \\
\hline 9 & $\mathrm{~K}$ & 1. 0 & .2 & 74.8 & 20.5 & 3.5 & ...... & 100.0 & 1,107 & 681 \\
\hline 10 & $\mathrm{~K}$ & 1.0 & .2 & 74.8 & 20.6 & 3.4 & -..... & 100.0 & 1,108 & .680 \\
\hline Avg & - n & 1.0 & 0.2 & 75.0 & 20.2 & 3.6 & -...- & 100.0 & 1,104 & 0.679 \\
\hline
\end{tabular}


TABLE 1.-Analytical data reported by the cooperating laboratories--Continued

LABORATORY NUMBER 24

A pparatus $\mathrm{V}_{1} \mathrm{R}_{1} \mathrm{Hg}$-Burrell

\begin{tabular}{|c|c|c|c|c|c|c|c|c|c|c|}
\hline \multirow{2}{*}{ Anal. No. } & \multirow{2}{*}{ Analyst } & \multicolumn{7}{|c|}{ Percentage by volume } & \multicolumn{2}{|c|}{ Calculated } \\
\hline & & $\mathrm{CO}_{2}$ & $\mathrm{O}_{2}$ & $\mathrm{CH}_{4}$ & $\mathrm{C}_{2} \mathrm{H}_{6}$ & $\mathrm{~N}_{2}$ & $\left(\mathrm{C}_{3} \mathrm{H}_{8}\right)$ & Total & $\mathrm{Btu} / \mathrm{ft}^{3}$ & sp gr \\
\hline $1 \ldots$ & $\mathrm{H}$ & 0.9 & 0.0 & 77.2 & 18.1 & 3.3 & 0.5 & 100.0 & 1,101 & 0.6714 \\
\hline $2 \ldots \ldots$ & $\mathrm{H}$ & 1.0 & .0 & 77. 2 & 18.1 & 3.1 & .6 & 100.0 & 1,104 & .6723 \\
\hline $3 \ldots$ & $\mathrm{H}$ & 1.0 & .0 & 76.7 & 18.5 & 3.2 & .6 & 100. 0 & 1,106 & .6751 \\
\hline $4 \ldots \ldots$ & $\mathrm{H}$ & 0.9 & .0 & 77.0 & 18.4 & 3.2 & .5 & 100.0 & 1,104 & .6727 \\
\hline 5 & $\mathrm{H}$ & 1.0 & .0 & 76.8 & 18.4 & 3.2 & .6 & 100.0 & 1,105 & .6749 \\
\hline 6 & $\mathrm{H}$ & 1.0 & .0 & 76.6 & 18.3 & 3.6 & .5 & 100.0 & 1,099 & .6749 \\
\hline 7 & $\mathrm{H}$ & 1.0 & .0 & 76.5 & 18.7 & 3.2 & .6 & 100.0 & 1,107 & .6762 \\
\hline $8 \ldots \ldots \ldots \ldots$ & $\mathrm{H}$ & 1.0 & .0 & 76.0 & 19.1 & 3.3 & .6 & 100.0 & 1,108 & .6779 \\
\hline 9 & $\mathrm{H}$ & 1.0 & .0 & 75.9 & 18.9 & 3.6 & .6 & 100.0 & 1,104 & .6785 \\
\hline 10 & $\mathrm{H}$ & 1.0 & .0 & 76.8 & 18.4 & 3.1 & .7 & 100.0 & 1,108 & .6754 \\
\hline Avg & $-\cdot$ & 1.0 & 0.0 & 76.7 & 18.5 & 3.2 & 0.6 & 100.0 & 1,106 & 0.6751 \\
\hline $1 \ldots$ & $\mathrm{C}$ & 0.9 & 0.0 & 77.1 & 18.1 & 3.2 & 0.7 & 100.0 & 1105.1 & 0.6731 \\
\hline $2 \ldots \ldots \ldots \ldots$ & $\mathrm{C}$ & .9 & .0 & 77.4 & 18.0 & 3.2 & .5 & 100.0 & 1101.2 & .6707 \\
\hline $3 \ldots \ldots$ & $\mathrm{C}$ & 1.0 & .0 & 76.9 & 18.3 & 3.3 & .5 & 100.0 & 1101.5 & .6735 \\
\hline $4 \ldots \ldots$ & $\mathrm{C}$ & 1.0 & .0 & 77.4 & 17. 9 & 3.0 & .7 & 100.0 & 1104.6 & .6723 \\
\hline $5 \ldots$ & $\mathrm{C}$ & .9 & .0 & 77.3 & 18.1 & 3.2 & .5 & 100.0 & 1102.0 & .6712 \\
\hline $6 \ldots$ & $\mathrm{C}$ & 1.0 & .0 & 77.2 & 18.2 & 3.1 & .5 & 100.0 & 1102.7 & .6722 \\
\hline $7 \ldots$ & $\mathrm{C}$ & .9 & .1 & 77.5 & 18.0 & 3.0 & .5 & 100.0 & 1102.3 & .6705 \\
\hline $8 \ldots$ & $\mathrm{C}$ & 1.0 & .0 & 77.0 & 18.3 & 3.1 & .6 & 100.0 & 1105.1 & .6737 \\
\hline - & $\mathrm{C}$ & 1.0 & .0 & 77.7 & 18.0 & 2.8 & .5 & 100.0 & 1104.3 & .6685 \\
\hline 10 & $\mathrm{C}$ & 1.0 & .0 & 77.2 & 18.4 & 2.9 & .5 & 100.0 & 1106.3 & .6724 \\
\hline Avg - & - & 1.0 & 0.0 & 77.3 & 18.1 & 3.1 & 0.5 & 100.0 & 1103.5 & 0.6718 \\
\hline
\end{tabular}

LABORATORY NUMBER 25

Apparatus $\mathrm{V}_{1} \mathrm{R}_{1} \mathrm{Hg}$-Burrell

\begin{tabular}{|c|c|c|c|c|c|c|c|c|c|c|}
\hline $1 \ldots$ & HRH & 0.90 & 0.00 & 75.41 & 19. 74 & 3.95 & ...... & 100.0 & 1099.4 & 0.6774 \\
\hline $2 \ldots$ & HRH & 1.00 & .10 & 77.71 & 18.05 & 3.14 & $\ldots$ & 100.0 & 1092.6 & .6671 \\
\hline $3 \ldots \ldots$ & HRH & 1.00 & .00 & 76.12 & 19. 20 & 3. 68 & -..... & 100.0 & 1096.9 & .6745 \\
\hline $4 \ldots$ & HRH & 0.90 & .00 & 78.09 & 17. 71 & 3. 30 & ...... & 100.0 & 1090.4 & .6646 \\
\hline $5_{\ldots} \ldots$ & HRH & .90 & .00 & 77.30 & 17.98 & 3.82 & ....... & 100.0 & 1087.3 & .6681 \\
\hline 6 & HRH & .90 & .00 & 76.90 & 18.57 & 3. 63 & ...... & 100.0 & 1093. 6 & .6702 \\
\hline $7 \ldots \ldots$ & HRH & .90 & .00 & 77.66 & 17.57 & 3.87 & ...... & 100.0 & 1083.6 & .6663 \\
\hline $8 \ldots .$. & HRH & 1.00 & .00 & 78.10 & 17. 39 & 3.51 & ...... & 100.0 & 1084.9 & .6649 \\
\hline 9 & HRH & .90 & .00 & 77.42 & 17.88 & 3. 80 & ...... & 100.0 & 1086.7 & .6675 \\
\hline 10 _ & HRH & .90 & .00 & 76.82 & 18.65 & 3.63 & -...... & 100.0 & 1094.3 & .6706 \\
\hline Avg - & & 0.93 & 0.01 & 77.15 & 18. 28 & 3. 63 & - . . & 100.0 & 1091.0 & 0.6691 \\
\hline
\end{tabular}

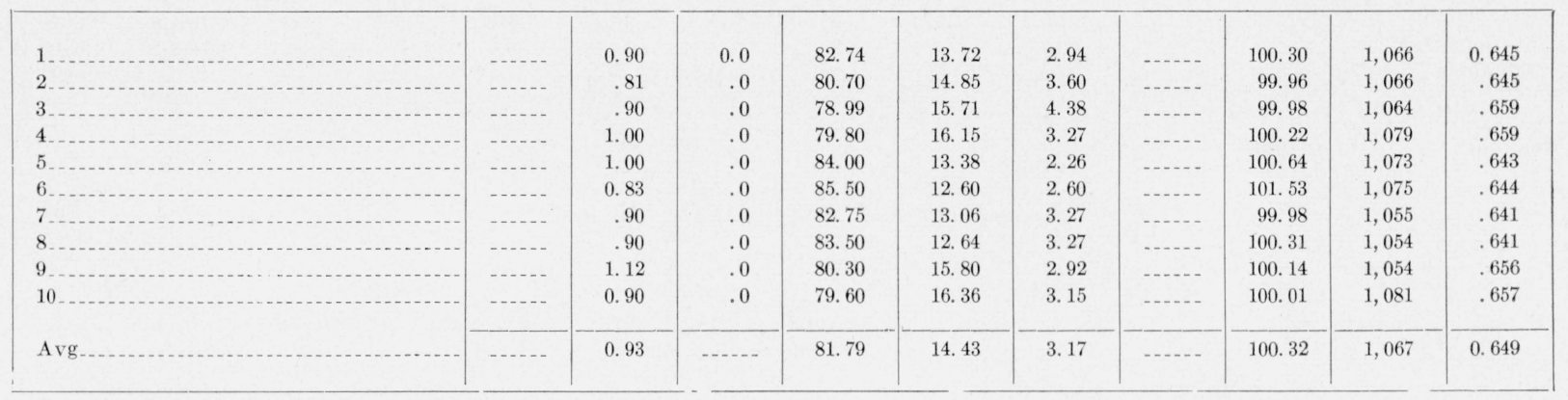


TABLE 1.-Analytical data reported by the cooperating laboratories-Continued

LABORATORY NUMBER 27

Method $A$

Apparatus $\mathrm{V}_{1} \mathrm{R}_{1} \mathrm{Hg}$-Burrell

\begin{tabular}{|c|c|c|c|c|c|c|c|c|c|c|}
\hline \multirow{2}{*}{ Anal. No. } & \multirow{2}{*}{ Analyst } & \multicolumn{7}{|c|}{ Percent by volume } & \multicolumn{2}{|c|}{ Calculated } \\
\hline & & $\mathrm{CO}_{2}$ & $\mathrm{O}_{2}$ & $\mathrm{CH}_{4}$ & $\mathrm{C}_{2} \mathrm{H}_{6}$ & $\mathrm{~N}_{2}$ & $\left(\mathrm{C}_{3} \mathrm{H}_{8}\right)$ & Total e & $\mathrm{Btu} / \mathrm{ft}^{3}$ & $\mathrm{sp} \mathrm{gr}$ \\
\hline 1. & $\mathrm{CMD}$ & 0.9 & 1.5 & 74.3 & 20.0 & 3.3 & $\ldots$ & 93.4 & 1092.86 & 0.6941 \\
\hline 2 & CMD & .9 & 0.9 & 73.3 & 21.5 & 3.4 & $\ldots$ & 94. 2 & 1109.27 & .6916 \\
\hline 3. & CMD & .9 & .9 & 69.1 & 23.9 & 5.2 & ....... & 93.7 & 1107.84 & .7071 \\
\hline 4. & CMD & .9 & .0 & $\ldots$. & $\ldots$. & 4. 7 & & 94.4 & . & -....... \\
\hline $5 \ldots$ & CMD & 1. 0 & .0 & $\ldots \ldots$ & ...... & 4. 9 & ...... & 94.1 & ........ & ....... \\
\hline 6. & $\mathrm{CMD}$ & 0.9 & .3 & n..... & n..... & 4. 8 & ....... & 94.0 & - n..... & ...... \\
\hline 7. & CMD & .9 & .0 & & ( & 4. 9 & $\ldots$ & 94.2 & $\ldots$ & ...... \\
\hline $8 \ldots$ & $\mathrm{CMD}$ & 1.1 & .0 & & & 4. 7 & ....... & 94.2 & & ....... \\
\hline$A \mathrm{vg}$ & & 0.94 & 0.45 & 72. 2 & 21.8 & 4. 5 & & 94.0 & 1103. 32 & 0.6976 \\
\hline
\end{tabular}

Methods $A$ and $X$

LABORATORY NUMBER 28

\begin{tabular}{|c|c|c|c|c|c|c|c|c|c|c|}
\hline \multirow{2}{*}{ Anal. No. } & \multirow{2}{*}{ Analyst } & \multicolumn{7}{|c|}{ Percent by volume } & \multicolumn{2}{|c|}{ Calculated } \\
\hline & & $\mathrm{CO}_{2}$ & $\mathrm{O}_{2}$ & $\mathrm{CH}_{4} \mathrm{e}$ & $\mathrm{C}_{2} \mathrm{H}_{6}$ & $\mathrm{~N}_{2}$ & $\left(\mathrm{C}_{3} \mathrm{H}_{8}\right)$ & Total & $\mathrm{Btu} / \mathrm{ft}^{3}$ & sp gr \\
\hline 1. & FWM & 1.00 & 0.05 & 73.30 & 21.55 & 4. 10 & (d) & 100.00 & 1110.2 & 0.6882 \\
\hline 2. & FWM & 1.05 & .00 & 73. 50 & 21.00 & 4. 45 & (d) & 100.00 & 1102.5 & .6871 \\
\hline 3. & FWM & 1. 00 & .05 & 74.45 & 20.75 & 3.75 & (d) & 100.00 & 1107.6 & .6828 \\
\hline 4. & FWM & 1.05 & .10 & 74.60 & 20.60 & 3.65 & (d) & 100.00 & 1105.4 & .6824 \\
\hline 5. & FWM & 1.05 & .05 & 75.10 & 19.90 & 3.90 & (d) & 100.00 & 1099.1 & .6797 \\
\hline $6 \ldots$ & FWM & 1. 10 & .05 & 74. 00 & 21.20 & 3.65 & (d) & 100.00 & 1111.0 & .6856 \\
\hline 7. & FWM & 1. 10 & .10 & 74. 40 & 20. 50 & 3. 90 & (d) & 100.00 & 1102.7 & .6834 \\
\hline 8 & FWM & 1.05 & .00 & 75.00 & 19.95 & 4.00 & (d) & 100.00 & 1099.0 & .6801 \\
\hline 9 & FWM & 1.00 & .10 & 75.10 & 19.55 & 4. 25 & (d) & 100.00 & 1092.9 & .6792 \\
\hline 10 & FWM & 1. 00 & .10 & 74.40 & 20.30 & 4. 20 & (d) & 100.00 & 1099.1 & .6827 \\
\hline$A \vee g$. & $\cdots$ & 1.05 & 0.05 & 74. 40 & 20.55 & 3.95 & (d) & 100.00 & 1103.0 & 0.6831 \\
\hline
\end{tabular}

Method $X$

\section{LABORATORY NUMBER 29}

\begin{tabular}{|c|c|c|c|c|c|c|c|c|c|c|}
\hline $1 .$. & $\mathrm{E}$ & $\mathfrak{f}_{0.8}$ & 0.2 & 77.1 & g 14.1 & 4. 8 & g 3.0 & 100.0 & 1092.8 & 0.6832 \\
\hline 2 & $\mathrm{E}$ & .8 & .3 & 76.8 & 14.1 & 5.0 & 3.0 & 100.0 & 1089.8 & .6346 \\
\hline 3. & $\mathrm{E}$ & .8 & .2 & 77.0 & 14.1 & 4. 9 & 3.0 & 100.0 & 1091.8 & .6837 \\
\hline $4 \ldots$ & $\mathrm{E}$ & .8 & .2 & 76.9 & 14.1 & 5.0 & 3.0 & 100.0 & 1090.8 & .6341 \\
\hline $5 \ldots$ & $\mathrm{E}$ & .8 & .3 & 77.1 & 14.1 & 4.7 & 3. 9 & 100.0 & 1092.8 & .6334 \\
\hline $6 \ldots$ & ...... & .... & ...... & ....... & ....... & 4. 88 & .... & ......... & ........ & ...... \\
\hline 7 & ....... & .... & ....... & ......... & & 5.0 & .... & ......... & ......... & ....... \\
\hline $8 \ldots$ & ...... & .... & ...... & ....... & ......... & 4. 7 & .... & - & ....... & ...... \\
\hline Avg. & $\ldots$ & 0.8 & 0.24 & 76.93 & 14.1 & 4.88 & 3.0 & 100.0 & 1091.6 & 0.6838 \\
\hline Maximum & ...... & .9 & .30 & 77.1 & - & 5.0 & -... & ......... & 1092.8 & 0.6846 \\
\hline Minimum & ....... & .7 & .20 & 76.8 & - & 4.7 & .... & -...... & 1039.8 & 0.6932 \\
\hline
\end{tabular}

See footnote at end of table. 
TABLE 1.-Analytical data reported by the cooperating laboratories-Continued LABORATORY NUMBER 30

Apparatus $\mathrm{V}_{1} \mathrm{R}_{1} \mathrm{Hg}$ and distillation apparatus

\begin{tabular}{|c|c|c|c|c|c|c|c|c|c|c|}
\hline \multirow{2}{*}{ Anal. No. } & \multirow{2}{*}{ Analyst } & \multicolumn{7}{|c|}{ Percentage by volume } & \multicolumn{2}{|c|}{ Calculated } \\
\hline & & $\mathrm{CO}_{2}$ & $\mathrm{O}_{2}$ & $\mathrm{CH}_{4}$ & $\mathrm{C}_{2} \mathrm{H}_{6}$ & $\mathrm{~N}_{2}$ & $\left(\mathrm{C}_{3} \mathrm{H}_{8}\right)$ & Tolal & $\mathrm{Btu} / \mathrm{ft}^{3}$ & $\operatorname{spgr}$ \\
\hline $1 \ldots$ & JHS & 1.05 & 0.05 & ... & & $\ldots$ & ... & & & ...... \\
\hline $2 \ldots \ldots$ & JHS & 1.00 & .00 & 79.7 & 15.0 & 0.0 & 4. 3 & 100.00 & b 1157,4 & 0.6817 \\
\hline $3 \ldots$ & JHS & 1.00 & .05 & ..... & n......... & -..... & -...... & ...... & -....... & -..... \\
\hline $4 \ldots$. & JHS & 1.00 & .00 & 81.6 & 14.5 & .0 & 2.9 & 100.00 & 1142.3 & .6651 \\
\hline $5 \ldots \ldots$ & JHS & 1. 00 & .00 & ...... & (......... & ...... & ...... & ...... & ....... & (n...... \\
\hline $6 \ldots \ldots$ & JHS & 1.02 & .00 & ..... & (n........ & ....... & -..... & ...... & ....... & -..... \\
\hline $7 \ldots \ldots$ & JHS & 1.00 & .00 & ..... & (......... & ...... & ....... & -...... & ....... & (....... \\
\hline $8 \ldots \ldots \ldots$ & JHS & 0.86 & .00 & ..... & ........... & ...... & -..... & ...... & ........ & ...... \\
\hline $9 \ldots \ldots$ & JHS & 0.97 & .00 & $\ldots$ & - & -..... & ..... & ...... & ....... & ...... \\
\hline $10 \ldots \ldots$ & JHS & 1.01 & .00 & -...- & - & -..... & -..... & -..... & - & -.... \\
\hline A vg & (n..... & 1.00 & 0.00 & 80.6 & 14.8 & 0.0 & 3.6 & 100.00 & 1155.2 & 0.6736 \\
\hline
\end{tabular}

a Erroneous result; apparatus not completely flushed with nitrogen in preparing for analysis.

b Gas sample exhausted after this analysis.

- Total combustibles; numbers 1, 2, and 3-wet manifold; numbers 5, 6, 7, and 8-dry manifold.

d Propane assumed absent.

e Total hydrocarbon volume determined by difference, nitrogen directly determined.

Obtained from average of absorption analyses.

s Ottained from fractionation analysis of small sample.

h Heating value computed, using given factors and analysis on dry basis. A verage heating value and specific gravity computed from average composition.

$i$ Analyst $B$ did not have enough time to complete any more of the analyses.

Washington, June 20, 1946. 